Portland State University

PDXScholar

1978

\title{
An Evaluation of HEW Grant 426, a Training Program for Foster Parents of Handicapped Foster Children
}

William McKee Thome

Portland State University

Follow this and additional works at: https://pdxscholar.library.pdx.edu/open_access_etds

Part of the Social Work Commons

Let us know how access to this document benefits you.

\section{Recommended Citation}

Thome, William McKee, "An Evaluation of HEW Grant 426, a Training Program for Foster Parents of Handicapped Foster Children" (1978). Dissertations and Theses. Paper 2642.

https://doi.org/10.15760/etd.2638

This Thesis is brought to you for free and open access. It has been accepted for inclusion in Dissertations and Theses by an authorized administrator of PDXScholar. Please contact us if we can make this document more accessible: pdxscholar@pdx.edu. 


\section{AN EVALUATION OF HEW GRANT 426; A TRAINING PROGRAM FOR FOSTER PARENTS OF HANDICAPPED FOSTER CHILDREN}

by

WILLIAM MCKEE THOME

A practicum submitted in partial fulfillment of the requirements for the degree of

MASTER OF SOCIAL WORK

Portland State University

School of Social Work

1978

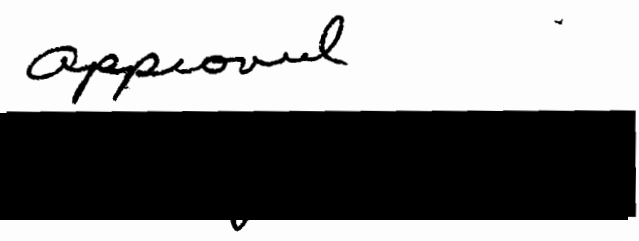




\section{ACKNOWLEDGMENTS}

I would like to thank Marie Lassell-Thome, for without her patience and hard work I would never have completed my graduate studies.

I would also like to thank my practicum adviser, Nancy Koroloff, for her professional guidance and concern. 
TABLE OF CONTENTS

PAGE

ACKNOWLEDGMENTS ................... ii

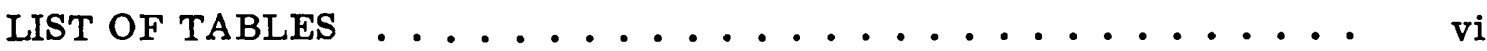

CHAPTER

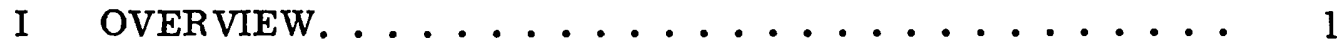

Introduction .................... 1

The Grant Proposal .............. 5

Implementation ................... 6

Training Program Description .......... 8

Evaluation Guidelines. . . . . . . . . . . 9

Evaluation Design and Collection. ......... 10

Evaluation Subject Areas. . . . . . . . . . 12

II FALL TERM. ...................... 14

Description of Class ............... 14

Class Evaluation . . . . . . . . . . . 17

Evaluation Results ............... 20

Part I........................ 20

Part II ....................... 24

Part III ......................... 27

Factors Affecting Attendance. . . . . . . . . 31

Conclusions. ..................... 32 
PAGE

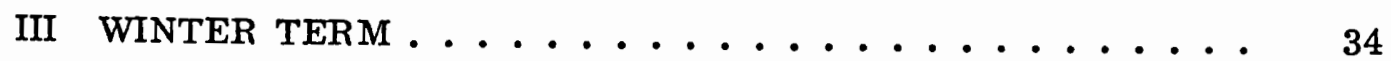

Class Objectives.................. 34

Description of Class Content ........... 35

Parent Profile .......................... 38

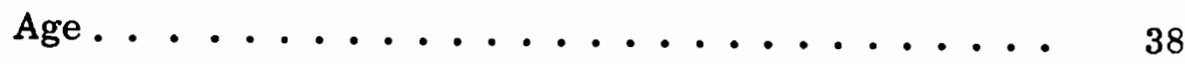

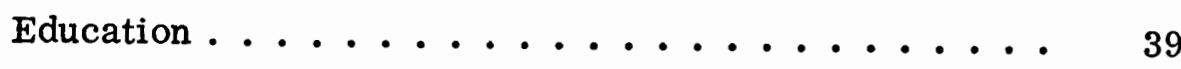

Number of Biological Children ........... 40

Family Income ................ 41

Class Evaluation................. 41

Evaluation Results................. 43

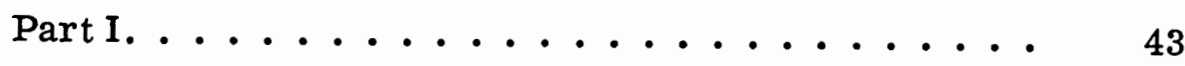

Part II ........................... 44

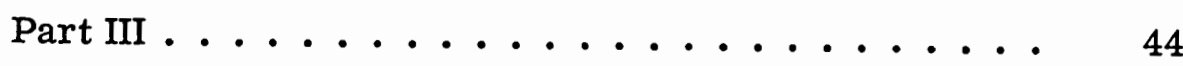

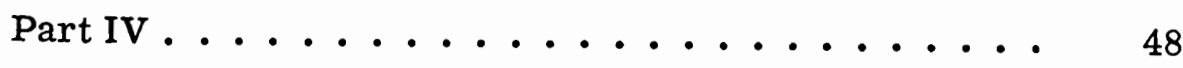

Results of the Pre and Post Learning Test. . . . . . 49

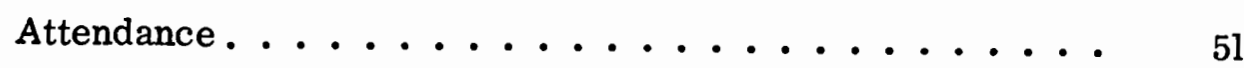

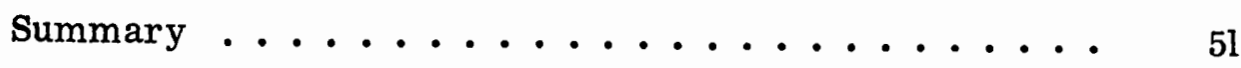

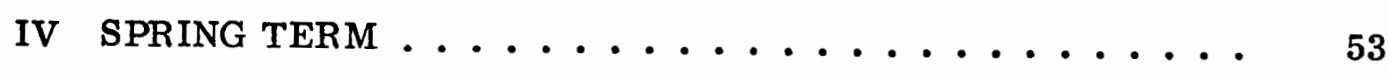

Description of Class............... 53

Class Content .................. 53 
PAGE

Class Evaluation ...................... 56

Evaluation Results ...................... 58

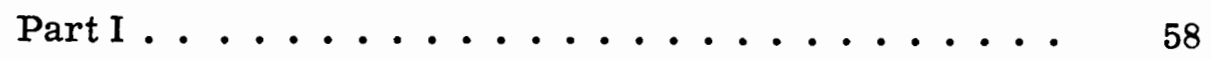

Part II ........................... 62

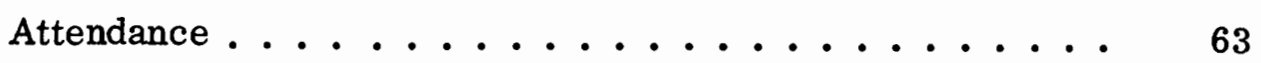

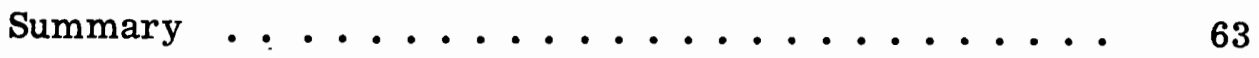

V SUMMARY AND RECOMMENDATIONS . . . . . . . . . 65

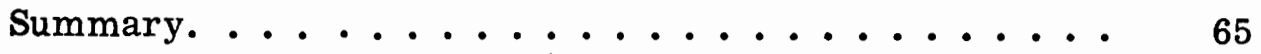

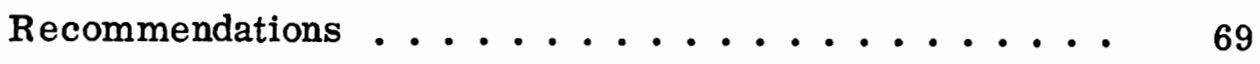

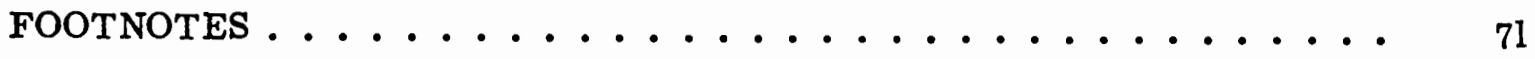

BIBLIOGR APHY . . . . . . . . . . . . . . . . . . . . 72

APPENDIX

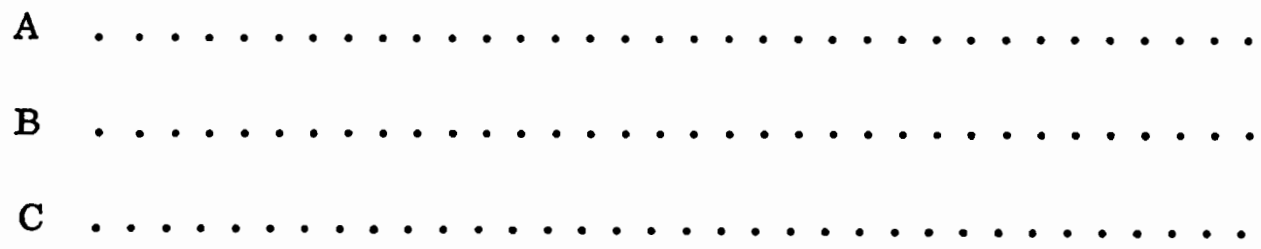




\section{LIST OF TABLES}

TABLES

PAGE

I Years of Experience as a Foster Parent . . . . . . . . 21

II Round-trip Miles Traveled by Parents to Class . . . . . . . 22

III Evaluation Results - Part II Statement A . . . . . . . 25

IV Evaluation Results - Part II Statement B . . . . . . . 26

V Evaluation Results - Part III Statements A, B, C . . . . . 30

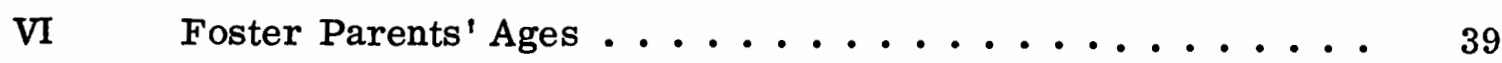

VII Years of Education _................... 40

VIII Number of Biological Children . . . . . . . . . . . 40

IX Family Income .................... 41

X Evaluation Results ....................... 45

XI $\quad$ Pre and Post Test Results ................ 50

XII Evaluation Results Part I ...................... 61 


\section{CHAPTER I}

\section{AN OVER VIEW}

\section{INTRODUCTION}

In 1969, the "President's Committee on Mental Retardation" issued a challenge to all those involved in the care and treatment of the mentally retarded, to integrate institutionalized children into ". . . normal community living . . . and enable them to develop their ability and potential to the fullest extent." 1 In addition to this mandate the federal government became increasingly aggressive in its campaign to make available to all handicapped children the same rights and privileges as "normal children". One of the major thrusts of this campaign today is to encourage local communities to commit themselves to fulfilling the needs of the handicapped individual within the environment of their community as opposed to the traditional method of institutionalization.

Unfortunately, this campaign was not met with complete success. For example, here in Oregon there are presently over 100 children 2 at Fairview Hospital and Training Center for the Mentally Retarded, who would be considered able to benefit from a "community placement" if one were available.

The move towards deinstitutionalization exerts additional pressure on the limited resources of the foster parent program. To meet the needs of these children, the Childrens' Services Division is challenged with a two-fold problem: 
First, they must generate public interest and involvement in special foster care, with a goal of enlisting more parents; and secondly, they must provide a more adequate system of training parents whose primary interest is working with handicapped children.

In Oregon, as in other states, the state administered foster-program assumes responsibility for the majority of foster children. Until the creation of the "Children's Services Division" in 1971, the responsibility for public foster care in Oregon was with the "Adult and Family Services Division". "CSD" evolved out of a national trend to separate financial assistance from social service programs. As a social service program, CSD is a combination of the Child Welfare Section of the Adult and Family Services Division, and the Juvenile Corrections branch of the Corrections Division, and the Child Study and Treatment Section of the Mental Health Division. This joining together of services under a single agency allows CSD to provide a comprehensive program of social services for children and families. CSD is mandated to

\footnotetext{
"administer, coordinate, develop, and provide social services for children and their families, essential to assure the physical, mental, emotional and social well-being of children. This is to be done while exercising a minimum of intervention in the family." 3
}

The execution of services is handled through forty-six CSD offices which are grouped into eight geographic regions.

One of the major responsibilities of the "Division", is the provision of substitute care and treatment services for children, which includes the annual 
certification of foster family homes. It is this certification that grants permission for parents to care for foster children in their homes.

The length of this care varies a great deal. Some parents are certified only for children needing temporary emergency care. While other children require intermediate-long term care; the goal of which is to work with the child and her/his family toward a resolution of the problems which necessitated the child's removal from the home. Other foster parents opt for planned, long term care, which is provided for those children who cannot live with their own families and are not eligible for adoption. As of August, 1977, CSD was providing foster care for "approximately 3, 417 children each day." 4 The average daily population of children placed in "special" foster homes, specifically certified for children with emotional and/or physical handicaps, was 451.

In attempting to gather specific data on the number of handicapped children in need of foster care, this evaluator experienced little success. In a telephone conversation, Loren Hoffman, Foster Parent Training Coordinator for CSD, stated that, "there is no specific information on the number of handicapped children awaiting placement every year." In regard to the availability of trained foster pare nts, he indicated that, because of the lack of appropriate homes, "many of the community's handicapped children in need of care . . . are placed in foster homes lacking the specialized training to adequately provide for their needs . . ."

The need for more intensive training has become a theme of specific concern to foster parent associations. Nationally, foster parent organizations are 
working to strengthen and clarify their role as caregivers. Their aim is to establish a firm sense of "professionalism" 6 in contrast to the ambiguity which has hindered their identification in the past. This ambiguity of role has impacted the "parent's self-image, as well as their interaction with the foster-child." 7

Historically, foster parents have encountered much role confusion. This was precipitated in part by public distrust of foster parent motives. For example, the commonly held assumption was that parents became involved in foster care "for the money." Foster care agencies both public and private nurtured this confusion with their assumption that foster parenting was a "labor of love," and that formal training was an unnecessary expense.

Researchers Kline and Overstreet, ${ }^{8}$ in formulating a professional rolemodel for foster care, differentiate between "primary" and "secondary" roles. 9 It is their opinion that foster care involves a complex network of interactions within which the foster parents "primary" function is to serve as a surrogate parent to the child, accompanied by secondary roles as employees of the agency, or, on occasion, as clients.

A. N. Muluccio ${ }^{10}$ takes issue with their suggestion that foster parents serve as clients. He contends that "practitioners reject the concept of foster parents as clients . . . and stress instead their role as agency employees." 11 The author goes on to suggest that:

"There has been a significant shift toward acceptance of foster parents as persons with special competence, and a valuable role in the process of foster care . . . (Foster parents are experiencing) more meaningful involvement in the formulation of agency policies, staff conferences, etc. . ."12 


\section{THE GRANT PROPOSAL}

In the state of Oregon, the "Foster Parent's Association" shares the nationwide concern among foster parents for more intensive training and the formation of a professional public image. As a reflection of this concern, leaders of Oregon's foster parent association met with Betty Leonard, of Oregon's Division of Continuing Education, in March of 1977 , to enlist her help in securing additional funds from the Childrens Services Division.

Ms. Leonard began her inquiry by discussing the Association's funding needs with CSD officials. She was told that CSD would be unable to expand its current funding base. From there, Ms. Leonard contacted HEW officials at Region Ten headquarters in Seattle, Washington, to explore the possibility of federal funding. She met with Mr. Jerry Saulter, Region Ten Director, who felt that grant monies might be available for the training of foster parents.

With the prospect of grant money from HEW, Ms. Leonard gathered together community and state professionals, with specific experience and knowledge of special foster care, to "brainstorm" ideas for a grant proposal. Out of this session evolved a federal grant proposal which outlined a plan for a pilot project involving the ". . . training of thirty foster home parents, certified by the Oregon Children's Services Division, to provide specialized foster care for handicapped children." 13

The committee proposed a training process which would consist of a specialized program designed to "increase the foster parents awareness of special resources in the community and increase their skills in working directly with the foster child in area of skill development and behavior management." 14 
It was further decided by the committee that the pilot project be limited to the four county area (CSD regions I and VIII) in and around the city of Portland. It was felt that the four counties selected; Multnomah, Washington, Columbia and Clackamas would present an excellent model for evaluating the feasibility of future expansion statewide.

Individually the counties have distinct qualities; Multnomah County with a population of 555,000 is the most populous in the state and contains large urban and suburban areas. Columbia County, though larger in square miles is quite rural with a population of only 28,790 .

Clackamas and Washington Counties both contain large rural areas with a rapid encroachment of bedroom communities presenting an increasing threat to the rural farm lands. Their populations are both rising rapidly with current estimates of approximately 200,000 each.

Travel distances from the outlying sections to the location of the training program in Portland are great. The square mileage of the four counties amounts to 3,662 ; presenting many of the foster parents with time consuming travel distances to class.

The final authorship of the grant proposal was a joint project of Ms. Leonard; Charlotte Duncan, Developmental Disabilities Service Coordinator for Multnomah County Mental Health; Thomas Orwick, CSD and Fairview State Hospital Laison; and Helen Ellsworth, Training Director for CSD, region VIII.

\section{IMPLEMENTATION}

As a result of Ms. Leonard's implementation skills, access to resources and her intensive work on the grant proposal, it was decided by her fellow grant 
authors that she assume directorship of the grant. Her colleague Barbra Lipkin was asked to serve as "project coordinator" assuming responsibility for the ongoing logistics of the training program, ie., attendance records, travel reimbursement, academic credit for those parents desiring such, initiation of advisory meetings, etc.

A "Planning Advisory Committee" was formed to develop a curriculum design. The selection of committee members was based on a recognized need for representation from the various agencies and associations responsible for the care of handicapped foster children. Thus the committee consisted of CSD and Mental Health coordinators from each of the four counties involved. In addition, members of the committee included a representative of the "four county Foster Parent Association" and a representative from the state CSD foster parent office, Thomas Orwick. It was decided at the initial committee meeting in June 1977 that the committee would meet once a month until the first class began in the fall. They would then meet at the end of each term to discuss the progress of the program and to weigh possible changes.

At the second meeting held in July, a "Selection Committee" was formed consisting of the four CSD representatives. Their responsibility was to expedite both the recruitment and selection of parents for the training program. In addition a "Media Development Committee" was formed to develop a "multimedia orientation package for the recruitment of new foster parents and the retention of foster parents that are interested in working with handicapped children. " 15 
The third committee meeting held in August heard a report on the Media Development Committee criteria for a filmstrip orientation presentation. Instructors for Fall and Winter Term were announced; Diane Plumridge of the Crippled Children's Division of the University of Oregon Medical School for Fall term and Pam Berki of the Carl V. Morrison Family Center for Winter term.

\section{TRAINING PROGRAM DESCRIPTION}

Because of the tremendous range and volume of material available on handicapped children, for example, developmental processes, and behavior management, the planning advisory committee was faced with a challenge. This challenge consisted of structuring a three term training sequence of sixty total hours, which would allow for both, coverage of the crucial elements and time for individual questions, and concerns of foster parents.

It was felt by the committee and class instructors that the crucial elements included a survey of childhood development, management of behavior and assessment of the handicapped child's capabilities, as well as advocacy and community resources. The greatest challenge, though, was reserved for the three teachers, for after determining the basic areas of instruction, it was the teacher's responsibility to plan and develop specific curriculum content.

The actual training program was divided into three terms, with each term consisting of ten, two-hour weekly sessions. Each term focused on specific foster parenting issues with the intent of producing a sense of continuity and consistency throughout the three terms. 
The first term concentrated on "Early Childhood Development." Special emphasis was made on the assessment of, and special treatment of, blind, deaf, mentally and emotionally disturbed, and non-ambulatory children. It was felt by the planning committee that this emphasis would assist the parents in assessing the impact of their foster child's handicap on their development and level of functioning.

Winter term was entitled "Living with the Handicapped Child, Skill Development, and Behavior Management." The instructor dealt with the process of skilldevelopment, and management of behavior problems. The importance of accurate assessment of the child's handicaps by the foster parent, was emphasized again this term. This emphasis was felt to be of particular importance because of its effect on the parents' approach to working with their foster children. This philosophy was based on the idea that accurate assessment by parents would maximize the child's developmental capabilities.

The third term was entitled "Community Resources". This course consisted of a survey of medical, educational, and recreational resources available to handicapped children in the four-county area. The course stressed the importance of, and the process by which the parents can serve as an advocate for their handicapped foster children.

\section{EVALUATION GUIDELINES}

In developing a design for evaluating the foster parent training program, a number of factors had to be considered. First it must be acknowledged that foster 
parents may not be similar in their attitude toward an evaluation process as other groups of adult learners. This attitude might include resistance to traditional modes of evaluation, such as performance testing. In this process, it is particularly important to design data collection procedures which will not intrude upon, nor negatively affect, the instructional process.

Secondly, because of the shift each term to a new instructor, and new subject matter, the cooperation and collaboration of the instructor was essential to the maintenance of continuity throughout the evaluation process. Their ongoing input regarding the parents and class content assisted this evaluator in sustaining some common data points over the three terms. These "data points" included the parents reaction to curriculum content and the content's impact on their own foster parenting situation.

A third factor was that the evaluation must provide useful data not only for the instructor but also the advisory committee, and the Division of Continuing Education. The evaluation process must be capable of providing information that can be used in planning future training sequences, grant requests, and also for the modification of the existing program.

\section{EVALUATION DESIGN AND COLLECTION}

During the early stages of the first training sequence, this evaluator contacted the Fall Term instructor to discuss possible evaluation designs with her. With the instructor's needs and suggestions in mind, this evaluator proceeded to review examples of class evaluations. After reviewing several evaluation formats, 
a three-part questionnaire was designed, which reflected both the evaluation factors referred to previously, and the instructor's needs and suggestions. (For a detailed description of the evaluation questions, refer to Chapter Two.)

The questionnaire was administered on the final evening of each term. In addition to the questionnaire, four of ten parents absent from the final class Fall term were contacted by this evaluator in order to administer the questionnaire and to discuss any possible logistical problems they had encountered during that term.

In the course of the First term, this eval uator also attended two of the classes, to talk informally with parents, and to observe the class process and content.

At the beginning of the Winter term, the parents were given a brief questionnaire requesting profile information such as age, education, income, etc. In addition this evaluator met with the Winter term instructor to brief her on the results of the Fall term evaluation, and to solicit her suggestions regarding the format of the evaluation for Winter term.

During Spring term, this evaluator contacted a sample of parents who did not return after Fall and/or Winter term, and of the parents who attended all three terms. The purpose of these interviews was to establish data pertaining to obstacles to attendance, and to collect additional feedback on the parents' attitudes about their training experience. In discussing the evaluation format with the Spring term instructor, she expressed satisfaction with the format for Winter term, so no additional modifications were instituted. 


\section{EVALUATION SUBJECT AREAS}

The following questions reflect the general areas of inquiry which were pursued in the evaluation process:

(1) Who is receiving training?

(2) What are they learning?

(3) What subject areas do parents find most valuable?

(4) How effective is the training format in conveying information?

(5) What effect is the training format having on the parents' relationship with their foster children?

Question \#l included such information as: age, education, income, number of foster children in the home and their types of handicaps.

Question \#2 refers to the content of the class, and whether the parents are assimilating the information provided by the instructor. Question \#3 is closely related to \#2, in that it asks: of the information the parents have received, what do they find most useful for their own situation? Results of this question will be particularly valuable for future training sequences, as they will pinpoint the content deemed most helpful to the parents.

Responses to Question \#4 will be useful in modifying the class during the year, and in planning for future classes. The information was gathered by assessing the parents' satisfaction, with the class location and time, class format and teaching aids. In addition, the parents were asked if problems with transportation and/or child care had any impact on their training. Included in this assessment category were those parents who attended fewer than two classes, for their input was particularly important for making future classes more accessible. 
Question \#5, regarding the training's impact on the parent's relationship with their foster children, was an important indicator of how, and to what degree, the training was being utilized and whether the training enhanced the parent/child relationship. It was also intended as an assessment of whether their increased knowledge base positively enhanced their self-image as a care-giver. 


\section{CHAPTER II}

FALL TERM

\section{DESCRIPTION OF CLASS}

The first series of classes began in the Fall of 1977 and were taught by

Diane Plumridge, M.S.W. The class was divided into ten sessions with Ms.

Plumridge teaching the introductory class, followed by eight weeks of guest

lectures. The lectures focused on the contrasts between normal childhood

development and various handicapping conditions which impact the child's growth and development. The tenth session was an informal one led by Ms. Plumridge, summarizing the Fall term. The Winter term instructor, Pam Berki, then discussed the format of her class.

Ms. Plumridge outlined the "specific objectives" of the class as being:

1. "to learn the general parameters of growth and biology (i.e., nature vs. nurture, general embryology, errors in development);

2. to learn normal developmental stages of childhood (i.e., motor and speech development, etc.);

3. to discuss the emotional development of all children, both normal and those with special needs;

4. to review the needs of adolescence and emancipation."

Ms. Plumridge additionally stressed that the course combined "both theory and pragmatic content," so that the parents would be able to develop specific skills which they could utilize with their own foster children. 
The following is a brief description of the content of the weekly guest speakers lectures.

October 4, 1977 Topic: "The Handicapped Child as a Person"

Guest Lecturer: Al Browder, M.D.

The format of this session was a panel discussion. The panel began by discussing the uniqueness of individuals which led into a discussion of how handicaps can impact a person's self-image and his functioning as an individual. The panel then proceeded to define and discuss specific handicaps; e.g., learning disabilities, mental retardation, developmental delay, and other delays.

October 10, 1977 Topic: "Child Development as Viewed by Three Theories and Causes of Abnormal Behavior"

Guest Lecturers: Sue White, Ph.D. and Honor Hughes, Ph.D. This session reviewed three theories of child development: "Psychoanalytic, Behaviorism and Cognition." They then proceeded to review Piaget's "Stages of Development" and possible abnormalities which might appear during the course of these stages.

October 18, 1977 Topic: "If Only He Could Talk, He'd Be OK"

Guest Lecturer: Warren Fay, Ph.D.

A review of normal speech development was presented including:

"communication, speech and language." Problems encountered in speech development were contrasted to that of normal development. A tape was then played, "Sounds in the First Year of Life," followed by questions and concerns of the parents. 
October 25, 1977 Topic: "Motor Development: How a Child Learns to Move His Body"

Guest Lecturer: Sue Giles, R.P.T.

This session was a discussion and definition of motor development and how movement handicaps develop. Definitions of specific handicaps such as cerebral palsy and spastic diplegia were augmented by both a slide presentation and video tapes.

November 1, 1977 Topic: "Seizures and Seizure Control"

Guest Lecturer: Mary Ellen Stranger, M.D.

This lecture centered on the "difference between and causes of seizures and epilepsy." A discussion of types of seizures, such as grand mal, minor motor and psychomotor was also included. Questions and concerns followed which included a discussion of medications used in seizure control.

November 8, 1977 Topic: "Feeding Clinic: The Mechanical and Nutritional

Problems of a Hard-to-Feed Child"

Guest Lecturers: Elaine Lis, Ph.D. and Merry Meek, M.S.

The lecture was divided into two parts. The theme of Part I was the relationship between the feeding process and the development of the total child. This included the role of occupational and speech therapists in assisting infants who are experiencing feeding difficulties. Part II covered the nutritional needs of children and how their individual needs are assessed. In conjunction with this, 
the parents were given ideas for eating exercises they could utilize to assist their foster children.

November 15, 1977 Topic: "The Emotional Problems of Development as Viewed by Erickson" and "How to Deal With the Severely Deprived Child"

Guest Lecturer: Jack Hegrenes, Ph.D.

The lecture was divided into three parts. Part I covered the "Emotional Stages of Development;" Part II consisted of "Play: Children's Work, " which was divided into types of play -- "exploratory," "competency," and "achievement." Part III was a discussion of the "Defense Hierarchy," and "Introjection, Phobias, Obsessions, Acting Out and Intellectualisms."

November 22, 1977 Topic: "Adolescence and Emancipation: The Normalization Process"

Guest Lecturer: Penny Mock, M.S., M.Ed.

This lecture dealt with the movement of youth out of "institutions and into society." Specific problems which the emancipated youth are likely to encounter, such as employment, socialization and marriage, were explored in a discussion format with the active participation of the class.

\section{CLASS EVALUATION}

In evaluating the class, there were six basic questions to answer: (l) how much experience do these parents have as foster parents; (2) what type of handicaps have they had experiences with; (3) what was their reaction to the content and 
instruction of the class; (4) was the format conducive to learning and appropriate to their particular situation; (5) what sort of logistical problems did they encounter in attending class (e.g., did transportation present a problem?); and (6) of those who dropped out, how many did so in response to the class; or, were logistical complications of transportation and/or childcare a factor in their decision to drop the class.

To most effectively evaluate the class, this evaluator first contacted Ms. Plumridge to get her specific suggestions. In addition, a review was made of other class evaluations. After taking into consideration Ms. Plumridge's suggestions and reviewing the various formats possible, this evaluator designed a threepart questionnaire to be filled out by the parents at the final session. (A copy of the evaluation is contained in appendix A.)

Part I consisted of six questions pertaining to the parents' specific situation; e.g., "how many years have you been a foster parent?" and ". . . how far do you have to travel round-trip to attend this class?"

Part II was a measurement of the parents' response to the individual lectures. The parents were asked to respond to two statements related to each of the lectures by selecting one of five responses ranging from "strongly agree" to "strongly disagree." The first statement measured the degree of relevancy the parent felt the lecture had to their specific situation and needs as a foster parent: "The speaker's lecture was helpful and/or informative to me as a foster parent." The second statement measured the lecturer's accessibility: The speaker made him/herself available for questions and concerns during and after class." 
The parents were then asked to select from the eight speakers who they felt was the most helpful and/or informative and the least helpful and/or informative.

The final question in Part II asked the parents if there was any among the eight speakers whom they ". . would particularly like to have lecture again next term." The responses to this question, would give additional feedback on lectures and subjects deemed most helpful by the parents, and would also assist in planning for future classes.

In Part III, three statements were presented in which the parents were instructed to respond to by selecting one of five responses identical to the five presented in Part II. The first statement measured the influence or effect of the class on the parents' relationship with their foster children: "This class has positively helped my relationship with my foster child/children."

The second statement measured the effect of the class on the parents' self-confidence as a foster parent: 'I feel more confident of myself as a foster parent after taking this class." The third statement was a measurement of whether the class enhanced the parents' skills as a foster parent: "The information and training I have received in this class will assist me in my work with handicapped foster children."

Following the third statement the parent was asked to "describe a specific situation in which the training you have received in this class has helped you." As an addendum to the written evaluation, the parents were instructed to fill out their name, address and phone number on a sheet accompanying the evaluation if they wished to be contacted by the evaluator to express additional positive 
or negative reactions about the class.

Of the 36 parents enrolled in the class, 20 attended the final session and filled out the evaluation. Of the remaining 16 , six (17\% of the total enrollment) had dropped out after attending fewer than two classes. Ten parents were still enrolled in the class but missed the final session. Of those ten, this evaluator was able to contact four of them and complete the evaluation over the phone. Therefore, of the thirty active class members, $80 \%$ responded to the questionnaire, with one respondent's evaluation being discarded for failing to sufficiently complete the evaluation.

EVALUATION RESULTS

\section{$\underline{\text { Part I }}$}

The responses to "What type of handicap or handicaps do your foster children have?" were very broad. The respondents listed a wide range of handicaps. The handicaps fell into two categories: physical and emotional.

The physical handicaps included such diverse categories as: "minimal brain dysfunction, cerebral palsy, failure to thrive, downs syndrome, heart disease, hydrocephaly, microcephalus, partial or total deafness and/or blindness."

The emotional handicaps included "autism, childhood type schizophrenia, behavior disorders" and the less specific category of "emotionally disturbed."

The response to the question regarding the number of years of experience as a foster parent was also quite broad. The parent's experience ranged from two who were "just beginning," to one parent who had 27 years of foster parent 
experience. It was also noted that thirteen (57\%) of the parents had between eight and twelve years of experience. Table One, below, reflects this broad range.

\section{TABLE ONE}

YEARS OF EXPERIENCE AS A FOSTER PARENT

\begin{tabular}{|c|c|c|}
\hline number of years & frequency & percentage \\
\hline $0-2$ & 3 & 13 \\
\hline $3-7$ & 3 & 13 \\
\hline $8-12$ & 13 & 57 \\
\hline $13-19$ & 1 & 4 \\
\hline $20-*$ & 3 & 13 \\
\hline TOTAL & 23 & 100 \\
\hline
\end{tabular}

$* 20,20,27$

Table Two suggests that the distance traveled by many of the parents could present potential logistical barriers impeding their attendance at classes. The average round-trip distance was 52.7 miles, with eight $(26 \%)$ of the parents driving in excess of 100 miles round-trip to attend classes. The distance traveled is particularly significant in that it adds considerably to the time the parents must allot to childcare for their foster children. In additi on, time spent traveling to class increases markedly as a result of winter driving conditions. 
TABLE TWO

\section{ROUND-TRIP MILES TRAVELED BY PARENTS TO CLASS}

\begin{tabular}{|ccc|}
\hline number of miles & frequency & percentage \\
\hline $0-25$ & 9 & 39 \\
\hline $26-50$ & 7 & 31 \\
\hline $51-75$ & 1 & 4 \\
\hline $76-100$ & 0 & 0 \\
\hline $101-125$ & 5 & 22 \\
\hline $126-*$ & 1 & 4 \\
\hline TOTAL & 23 & 100 \\
\hline
\end{tabular}

Four of the parents wrote of the problems they encountered traveling to and from class:

"The problem is the distance... the time gone from home, the possibility of bad weather." This quote was from a couple who drove 138 miles to attend class.

"The distance is a problem (47 miles), especially since I have to travel at night."

"I don't drive; if I miss the 9:27 Tri-Met (city bus) from the medical school (location of class), I have to wait downtown until 10:27 p.m. to get home. . . I often had to rely on others from class for rides." 
"We drove 74 miles to attend classes, which can be quite hazardous when the weather is foggy."

Just over $30 \%(7)$ of the parents responded to the question regarding "difficulty getting childcare" while attending class, by describing problems they have encountered.

"(I) live in a rural area ... often unable to locate a suitable babysitter, so I filled in with relatives."

"Sometimes (I) have trouble getting a suitable sitter."

"I have problems locating good childcare and when I do, it's often very expensive. In my situation, the sitter must come to my home---often they don't want to sit with my children because they're scared by the fact that my foster children are oftèn teenagers and multiply handicapped."

"Yes. - our deaf foster youngster being controllable by a reticent motherin-law babysitter."

"If my daughter is available it's okay. If not, no one willingly will keep them because of behavior problems. (I) missed two classes because of this." "Finding a sitter is complicated. I finally found one through the local high school, but it cost me five dollars for three hours."

"There is a hesitancy on the part of babysitters to take responsibility for our deaf/emotionally disturbed child. He presents a management problem even for those who have some manual communication."

Some parents were able to secure a solution within their own family. "My husband babysat." 
"My daughter agreed to babysit for a fee."

"We have a built-in babysitter."

"At the moment my college daughter is able to sit evenings as she goes to community college."

In reviewing the above comments, it becomes apparent that each family faces a unique challenge in securing childcare. A challenge that tests the parents' resourcefulness, financial situation, and/or availability of cooperative family members.

\section{Part II -- Evaluation of Guest Lecturers}

The parents' response to the individual lectures was very positive. The percentage who responded positively to the statement regarding "degree of relevancy to their own situation," ranged from a high of $96 \%$ for the lecture of "Child Development," to $73 \%$ for the lecture on "Teenage Emancipation." Of 156 responses to eight lectures, there was only one response which "disagreed" with the statement. (Refer to Table Three)

Judging from comments made to this author, the majority of the 17 "undecided" responses were reacting to whether the content was appropriate to their specific situation as opposed to suggesting that the lecturer and his/her content were poor.

"The foster children I work with are teenagers, so the classes that talked about feeding infants and early speech development were interesting but it's not information I can use." 
TABLE THREE

Part II Statement A

"The Speaker's Lecture Was Helpful and/or Informative To Me As a Foster Parent."

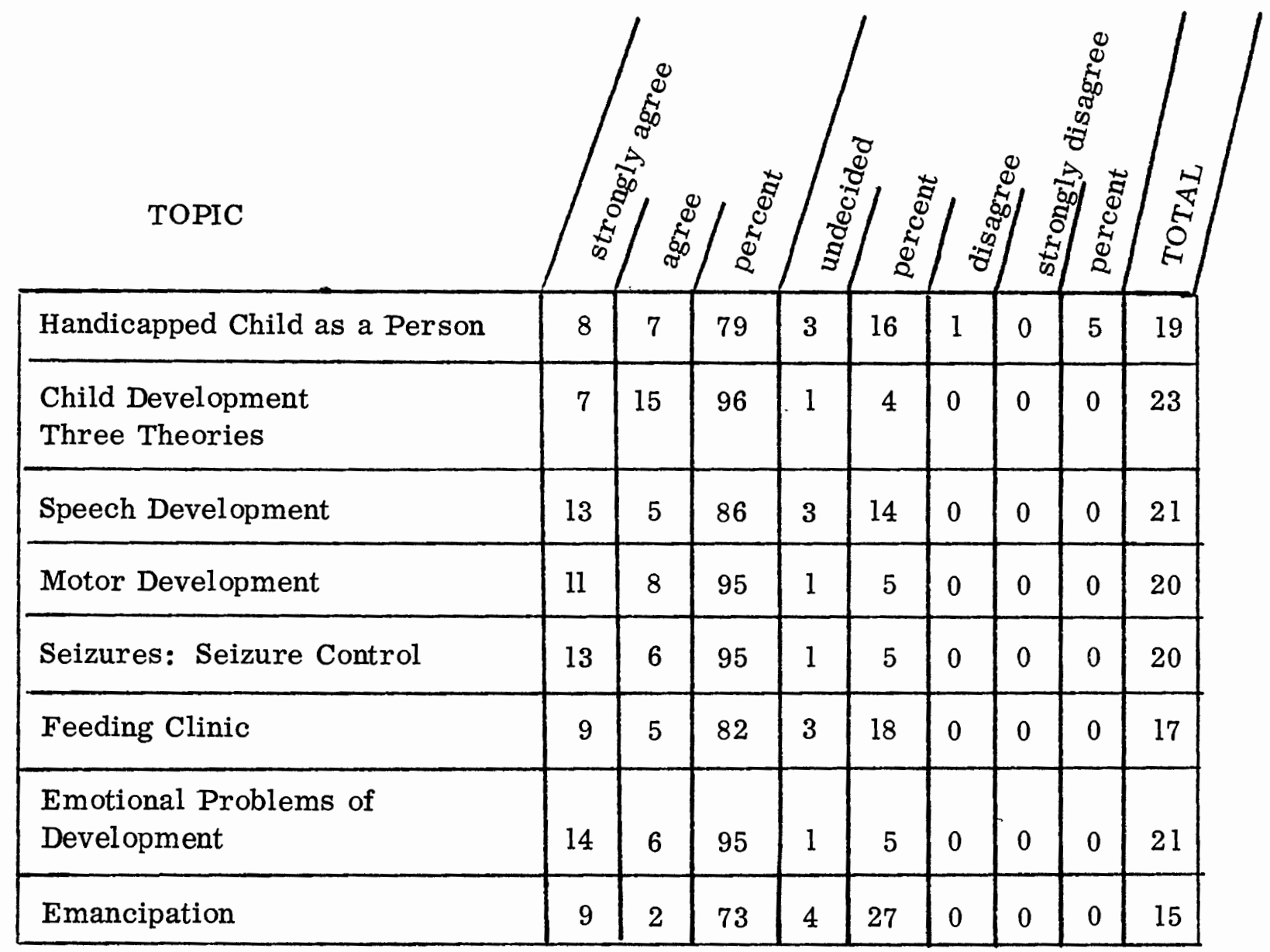




\section{TABLE FOUR}

\section{Part II Statement B}

"The Speaker Made Him/Herself Available for Questions And Concerns During and After Class."

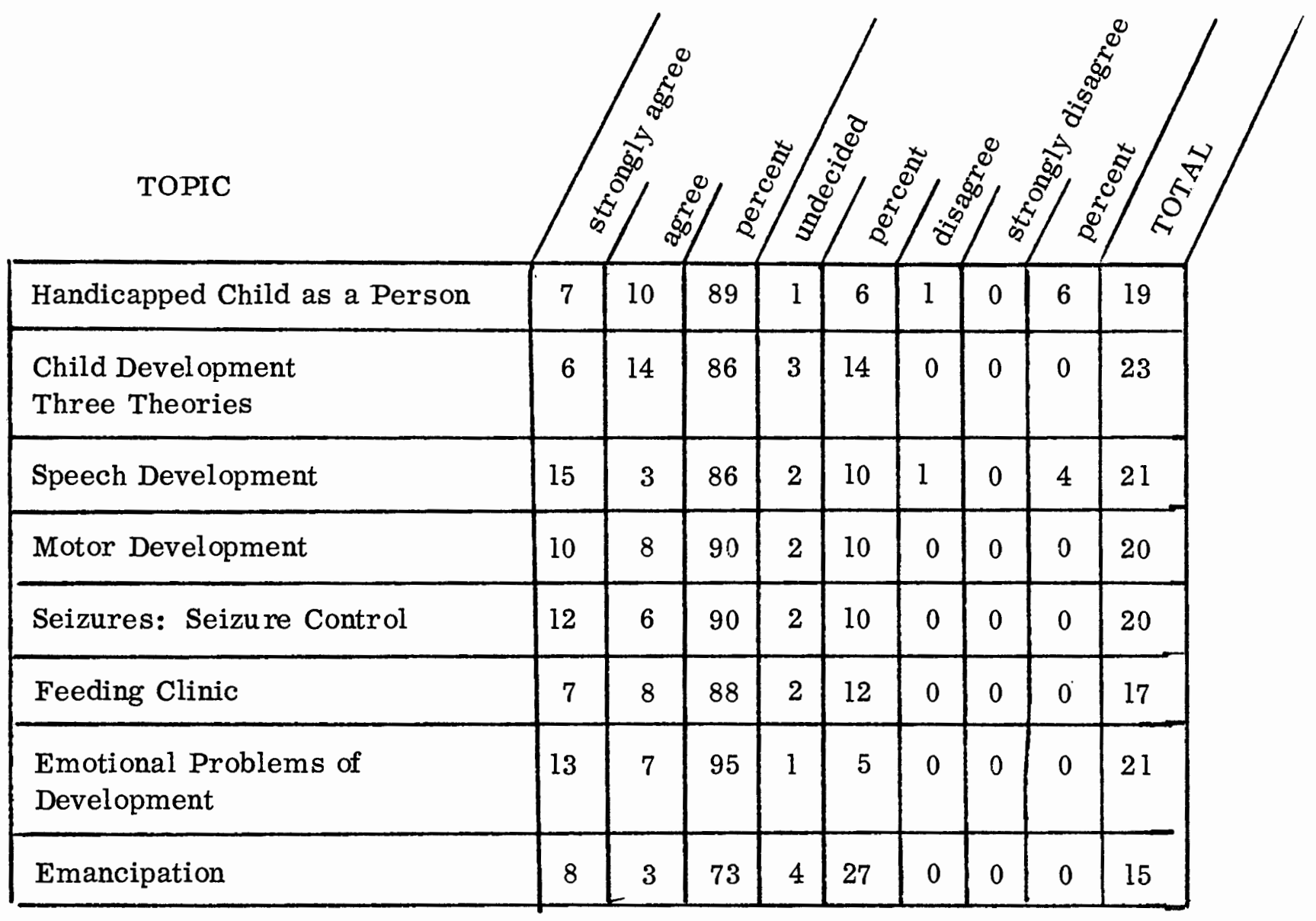


". . my foster children are emotionally disturbed . . many of the classes were very informative, but it wasn't information I could put to use in my situation."

The response to the next statement regarding the lecturer's accessibility was also very positive. The percentage of positive responses was virtually identical to those shown in Table Three with the highest response being $95 \%$; the lowest, $73 \%$.

The response to the question, who was the "most helpful and/or informative speaker, " reflected the broad scope of interests among the parents. Two of the eight topics received ten votes each, with three others close behind with seven votes each. Thus, five of the eight speakers were given strong endorsements by the parents, as opposed to one speaker dominating the responses. This pattern is also a reflection of the wide range of handicaps these parents deal with as indicated in Part I.

\section{$\underline{\text { Part III }}$}

Table Five outlines the responses to the three statements presented in Part III. The number of positive responses to statement $\mathrm{C}$ is significantly higher than statements $\mathrm{A}$ or $\mathrm{B}$, with $\mathrm{A}$ having the lowest positive responses.

It is this evaluator's opinion that the lower positive response for A and B is a reflection of the nature of the first two statements. Statement $A$ asks the parents to reflect on whether the class has positively helped their relationship with their foster children. Statement B asks them to reflect on whether they, as foster parents, "feel more confident" as a result of the class experience. Whereas 
statement $\mathbf{C}$ is more global and does not ask the parent to specifically reflect on their present situation. Thus the parents who were "undecided" or disagreed with the first two statements were very possibly the same parents who felt their own situations were not sufficiently covered by the lectures. Consequently, they felt their own parent/foster child relationships were not enhanced as a result of the classes.

Over half of the parents, thirteen $(57 \%)$, responded to the request, in Part III to "describe a specific situation ..." The responses were quite varied with some describing specific situations as requested, while others took the opportunity to describe their general impressions of the class.

Some of the "specific situations" the parents shared were:

"I have one child that has trouble with masturbation. Through the slides and lecture, I have been better able to explain to (the) child that there is a place and time when it's not so wrong and a place where it is not acceptable."

"My developmentally disabled foster child has seizures and I obtained names of seizures, what to expect, and how to help her and what medications can be helpful."

'I presently have a four-year-old who is a failure to thrive child. Discipline had always been a major problem with him . . . I didn't know how to deal with him. The classes have helped me to set specific limits and to develop a consistent system of discipline with him."

General impressions included: 
"Being a trained teacher of the deaf and having worked with multiply handicapped kids for over 11 years, this class has been (both) stimulating and a good review for certain new facts relating to differing subjects."

"The Speech Development (class) of October 18 was so excellent that I felt he opened a new door for me in understanding."

"Foster children have such a strong self-protection impulse that family relationships can deteriorate. Dr. Hengrenes' talk settled in my mind how best to deal with such situations."

"I have really enjoyed the classes. All of them have provided some information that if not used immediately, will benefit future children in our home." 


\section{TABLE FIVE}

Part III Statements A, B and C

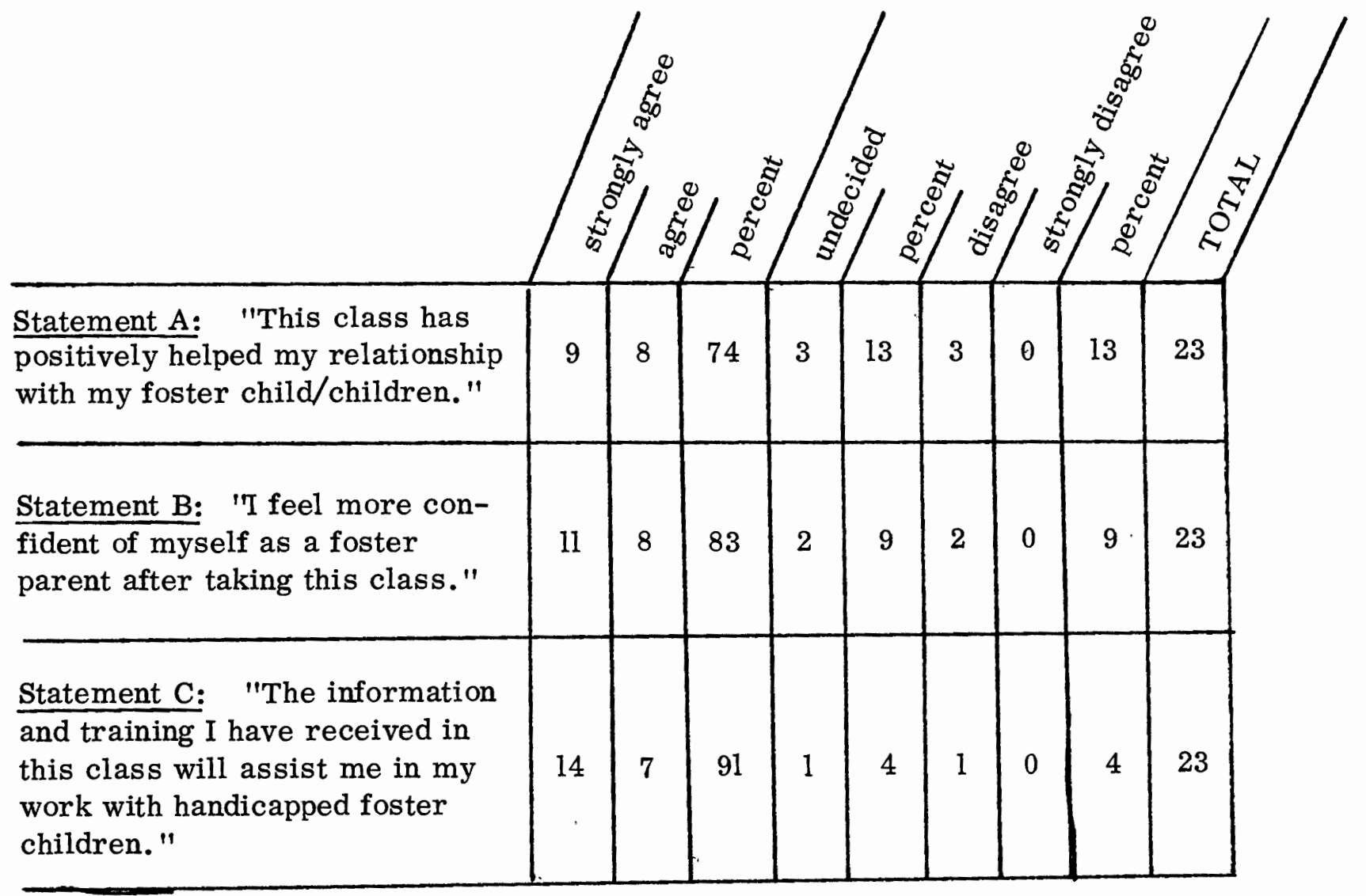




\section{FACTORS AFFECTING ATTENDANCE}

Six of the 36 parents enrolled attended two or less of the ten class sessions. In contast to this, twenty (67\%) of the parents attended at least eight of the ten classes. To best evaluate both the strengths and weaknesses of the class, feedback from those who dropped out was essential. This evaluator was able to collect feedback from four of the six parents via telephone.

The biggest issues for these parents were transportation and childcare. A mother of two pre-schoolers, and foster mother to as many as four handicapped children at one time, stated:

'I live thirty miles from class ... this time of year there is often snow out this way which makes traveling at night treacherous."

Regarding childcare she stated: " . . paying a sitter is even a bigger problem than getting to class. It costs me ten dollars to pay a sitter to watch my children while I'm at class. I just couldn't afford it every week, so I had to stop going."

Another foster mother related: "I couldn't find anyone to sit with my teenage foster child. She was a runaway risk and no one wanted to take the responsibility. Childcare is a real problem ... I also had transportation problems; my car broke down twice and was in the shop for two weeks. I had no way of getting to class."

The remaining two parents contacted, experienced logistical complications of distance and weather, compounded by the class being held at night. 


\section{CONCLUSIONS}

In reviewing the overall tone of the parents' responses, it seemed that the majority of the parents were satisfied with the structure and content of the fall sessions. Perhaps the only factor affecting this positive tone was the parents (four in number) who expressed a need for a more comprehensive representation of older children in the content of the lectures. This concern coupled with the extremely diverse categories of handicaps which the parents are involved with, makes curriculum planning a very real challenge.

Logistical complications appear to be a multi-faceted problem judging from the feedback received from class participants. It is apparent that the location of the clas's dramatically affects the parents' ease of accessibility. A possible solution to this problem would be "satellite" classes which could be set up in the four-county area. These satellites could take advantage of already-existing facilities, such as community colleges or high schools. This concept could be used as a possible model for a statewide program of training. This satellite concept would simplify accessibility and would cut down on the time the parents would have to allot for traveltime and, consequently, childcare. Additionally, the matching up of parents in a car-pooling program would be of help to those who do not ot herwise have access to transportation.

A possible solution to the complications of childcare might also be found through the satellite concept. Community-based classes could provide childcare at the class site. Some children, though, may have handicaps which necessitate 
specific attention and care which can best be met in the parents' home. A solution might be to offer a comprehensive list of "sitters" capable of caring for the prescribed needs of these children. 


\title{
CHAPTER THREE
}

\author{
WINTER TERM
}

\section{CLASS OBJECTIVES}

The Winter term series of classes was taught by Pam Berki. The class was divided up into ten sessions with Ms. Berki assuming teaching responsibility for all but one session. The title of Ms. Berki's sequence was: "Living With the Handicapped Child; Skill Development and Behavior Management." The general objective for the class (contained in the "course syllabi" and distributed to the students) was:

"The second quarter will focus on helping the foster parents acquire practical knowledge of behavior management and skill acquisition to enhance their ability to work with their handicapped children. In addition foster parents will be given information on the tools most commonly used in assessing handicapped children and how to use information acquired through assessment to maximize their child's development."

The specific objectives were:

(1) "To learn basic concepts of behavioral theory and practical applications of behavioral technology in working with their children.

(2) To develop skills in task analysis for use in areas of self help skills, survival skills, language development and motor skills.

(3) To learn about infant stimulation and to become familiar with packaged materials available for use with infants and preschool children.

(4) To become familiar with materials and tests used in the assessment of handicapped children and to be able to use 
information received from these assessments to develop a working plan for an individual child.

(5) To gain skills in behavior management and to develop a repertoire of skills for dealing with behavior problems in children who range developmentally from one year to eighteen years."

\section{DESCRIPTION OF CLASS CONTENT}

The following is a brief summary of weekly class content: January 10, 1978 Topic: "Learning Theory: A General Outline"

The first session of class focused on defined behavior and the process by which behavior is learned. Included in the discussion was a description of both the antecedents and consequences of behavior and how to establish a baseline for behavior from which the parent can work towards a behavior goal for a child.

January 17, 1978 Topic: "Learning Theory"

The session opened with a film dealing with "task analysis and skill breakdown." The parents were then divided into groups to discuss and fill out a work sheet on task analysis. After the groups had completed their assignment, the instructor lectured on the process of pinpointing behavior, goal setting, and reinforcement.

January 24, 1978 Topic: "Behavior Management"

This session began with a discussion of the "learning chain; cue-behaviorconsequence." This discussion led into the "goals of misbehavior; A.G.M. (Attention getting mechanisms)." These include, "power, revenge and inadequacy 
or assumed disability" and their relationship to the four categories of behavior problems; "non-compliant, aggressive, self-indulgent, and self-stimulating."

January 31, 1978 Topic: "Behavior Management" (continued)

This session was divided into two components. The first component was a presentation by the instructor of material on "behavior programs" for "young/ delayed children," then behavior programs for older children. The second component involved the dividing of the class into small groups to discuss two case examples of specific behavior problems.

February 7, 1978 Topic: "Infant Stimulation"

The session began with a video-tape demonstration of the "Denver Developmental Screening Test (DDST)." This was followed by a discussion of the "Portage Guide to Early Education, " a home based teaching model for use with parents/ families and their handicapped children ranging in developmental age from birth to six years. After a brief break the instructor presented an introduction to the "Down's Syndrome Infant Program."

February 14, 1978 Topic: "Testing"

Guest Lecturer: Dr. Y. A. LaClaire

This session was unique this term in that the instructor had a guest lecturer speak. The lecture was divided into three parts: (1) a general introduction, (2) "the parents' role in psychological testing, (3) types of psychological tests; "Intelligence tests, Personality tests, Perceptual/Neurological tests, and Achievement tests. To assist the parents understanding of the tests, printed material on 
each of the tests was distributed. This material included a brief description of each of the tests. And a case example of a psychological evaluation.

February 21, 1978 Topic: "Language Development"

The instructor began by discussing the three major areas of language, "receptive, expressive, and cognitive." The causes of dysfunctional language and its "consequences" were then presented. Incorporated into this was a survey of normal language development. The instructor concluded with a discussion on how to deal with a child who is experiencing "delayed language" problems.

February 28, 1978 Topic: "Alternate Language Systems"

The first half of class focused on "alternate language systems;" these systems consisted of "picture communication systems" and the various types of "sign" language. In the second half of class the instructor worked with the parents individually and in small groups discussing the specific communication needs of their own foster children.

March 7, 1978 Topic: "Bridging the Gap"

This session began with a survey of communication skills, both verbal and nonverbal. This was followed by a discussion of how the foster parents could work with natural parents; what to do to help their foster child's transition from one placement to another and how to deal with the uncertainties of placements.

\section{March 14, 1978 Topic: "Social Skills"}

The first half of class involved a discussion of how the parents could help 
their children develop appropriate public behavior, develop friendships and avoid "set-ups" by their peers. The second half consisted of a brief summary of the Winter term's content.

\section{PARENT PROFILE}

At the initial meeting of class, Winter term, the parents were given a brief questionnaire which asked for some basic profile information. (For copy of the test see Appendix C) The profile categories included: age, highest grade completed in school, family's net income, number of biological children and number, if any, of handicapped children. Twenty-one of the twenty-nine parents enrolled responded. Of the 21 respondents 15 were returning from Fall term.

$\underline{\text { Age }}$

The age range of the parents was quite broad with the youngest parent thirty-five years old, the eldest sixty-five. In examining this age range, the question arose, as to why there was no one under the age of 35 enrolled. Minimum age, for foster parents, as set by CSD, is twenty-one.

This evaluator contacted Loren Hoffman, a "Foster Parent Training Coordinator," Region 8 of Children Services Division of Oregon, to get his opinion on the absence of younger parents in the training program. It was $\mathrm{Mr}$. Hoffman's impression that the 'younger' parents tend to be enlisted as providers of emergency shelter care and for children who have no physical limitations. He added that as the parents gain experience they often begin to specialize in a specific area of foster care. Those who choose handicapped foster children often 
have been involved in foster care for a number of years. He described these parents as often having a desire to strengthen their practical knowledge and add a sense of professionalism to their role as a foster parent. This data was consistent with the data from Fall term which indicated that $74 \%$ of the parents had had at least eight years of foster care experience.

TA BLE SIX

FOSTER PARENTS' AGES

Age Frequency

Percentage

$35-39$

5

24

40-44

4

19

$45-49$

3

14

50-54

6

29

55-59

1

5

60- *

2

9

* 65

$N=21$

$100 \%$

\section{EDUCATION}

The parents' educational background was quite diverse. Thirty-eight percent (eight) of the twenty-one parents did not finish high school. Another thirtyeight percent attended college with two completing Masters level programs. The average for the class was twelve years of school. 
TABLE SEVEN

YEARS OF EDUCATION

No. of Years Frequency

Percentage

$$
0-8
$$

2

10

$9-12$

11

52

$13-16$ 5

24

$17-18$

3

14

$$
\mathrm{N}=21
$$

$100 \%$

\section{NUMBER OF BIOLOGICAL CHLDREN}

All 21 of the parents enrolled had at least one child of their own; seventy percent had between three and six children. One couple had fourteen natural children. Only four (19\%) of the parents polled had children of their own who are handicapped.

TABLE EIGHT

NUMBER OF BIOLOGICAL CHILDREN

No. of Children Frequency

$$
0-2
$$

4

20

$3-4$

7

35

$5-6$

8

40

7 - * 
FAMILY INCOME

The parents were given five income levels from which to select the one which most accurately reflected their own. The income levels began at zero and climbed in increments of $\$ 5,000$. It was noted that as a whole, the majority of the class, $(65 \%)$ earned an income (15 to 20,000 dollars) approximating that of the national average for a middle income family of four. It was also noted though, that twenty-five percent of the respondents earn significantly less than the national average, under 10,000 dollars a year.

TABLE NINE

FAMILY'S NET INCOME

Annual Income

0

$5,000-9,999$

$10,000-14,999$

$15,000-19,999$

$20,000-+$
Frequency

1

4

2

11

2
Percentage

10

\section{CLASS EVALUATION}

In developing an evaluation for Winter te $\mathrm{rm}$, this evaluator retained the basic format of the Fall term evaluation, in order to maintain a consistent data base on which to evaluate the entire sequence. To maintain consistency two questions had to be addressed; (1) What was the parents' reaction to the content and 
instruction of the class, (2) was the class format conducive to learning and appropriate to the participants particular situation. In addition, the parents were again asked whether they had encountered logistical problems with childcare and/or transportation.

The Winter term instructor, Pam Berki was contacted for her suggestions and for a description of class content. Her assistance included the development of a pre and post test for the parents. The pre-test measured their knowledge of "Skills development and Behavior Management" before the beginning of classes. The post-test measured the amount of learning the parents experienced as a result of the ten week course. Ms. Berki granted permission for the results of her tests to be used as a part of the overall evaluation process.

The questionnaire developed by this evaluator was divided into four parts. Part I was given only to those parents who did not attend Fall term, and consisted of questions pertaining to the parents' specific situation; round trip travel distance to and from class, how many years as a foster parent and whether transportation and/or the availability of childcare presented any problems for them.

Part II was designated for parents returning from last term only. They were asked if they encountered logistical problems last term and if so, have they found a solution this term. It was hoped that this might produce some input for future planning of classes.

Part III consisted of a list of topics covered by the instructor Winter term. The parents were presented with the same statement as was used Fall term: "The speaker's lecture was helpful and/or informative to me as a foster parent" 
and asked to respond to it by choosing one of five responses varying from "strongly agree" to "strongly disagree." Since there was only one guest lecturer the latter statement from Fall term regarding the speaker's "accessibility" was removed and placed at the end of the topic headings that the parents were instructed to evaluate.

Placed at the bottom of Part III were three questions pertaining to class content; "was your children's age group sufficiently covered," "which of the topics was most helpful and/or informative to your situation," and "was there a topic you wish had been covered in class that was not."

Part IV was a repeat of three statements presented in Fall term's evaluation. The first statement was a measure of the influence or effect of the class on the parent's relationship with their foster children; the second measured the effect of the class on the parent's self-confidence as a foster parent; the third was a measurement of whether the class enhanced the parent's skills as a foster parent.

Following the third statement the parent was invited to make "any additional comments either positive or negative," regarding the class.

Of the twenty-nine parents enrolled in the class, twenty-four (83\%) were present at the final session and filled out the evaluation. Of the twenty-four, eight (33\%) had not participated in the class during Fall term.

\section{EVALUATION RESULTS}

Part I:

In collating the results to Part I it was discovered that the parents (new to the 
class Winter term) range of experience was both narrower (fourteen years as opposed to twenty-five years) and the mean smaller ( 7 years) as compared to the Fall term (11 years).

The distance travelled by the new parents was appreciably shorter with a range of nineteen miles and a mean distance of twenty-one miles; in comparison the Fall term range was 128 miles with a mean distance of fifty-three miles. In conjunction with the abbreviated travel distance of the new parents polled, an absence was noted of any transportation difficulties under question number three.

In regards to question number four; ". . . any difficulty getting childcare for your foster children," the parents again denied experiencing any logistical problems, though two parents did allude to having a potential for complications in the future:

'I would have had a very hard time getting a sitter but my mother has been staying with me, so was able to attend this term. If it (was) not for her, it would have been impossible to find a sitter. They have all left the country, I think."

". . Would have had a problem but my husband took care of the children and he said he is getting tired of babysitting."

$\underline{\text { Part II: }}$

Part II was filled out only by those parents who attended Fall term. Of the sixteen respondents, none expressed having experienced any difficulty with either transportation or childcare.

Part III:

The parent's response to the sessions this term were even more positive 
than last. Five (50\%) of the class sessions received a positive resp onse of $100 \%$. Of the remaining five sessions the lowest positive response was $84 \%$. Of the 213 total responses of ten class sessions there were no respondents who "disagreed" with the statement and only thirteen who were "undecided" regarding a particular class.

\section{TABLE TEN}

"The Speaker's Lecture was Helpful and/or Informative To Me As a Foster Parent."

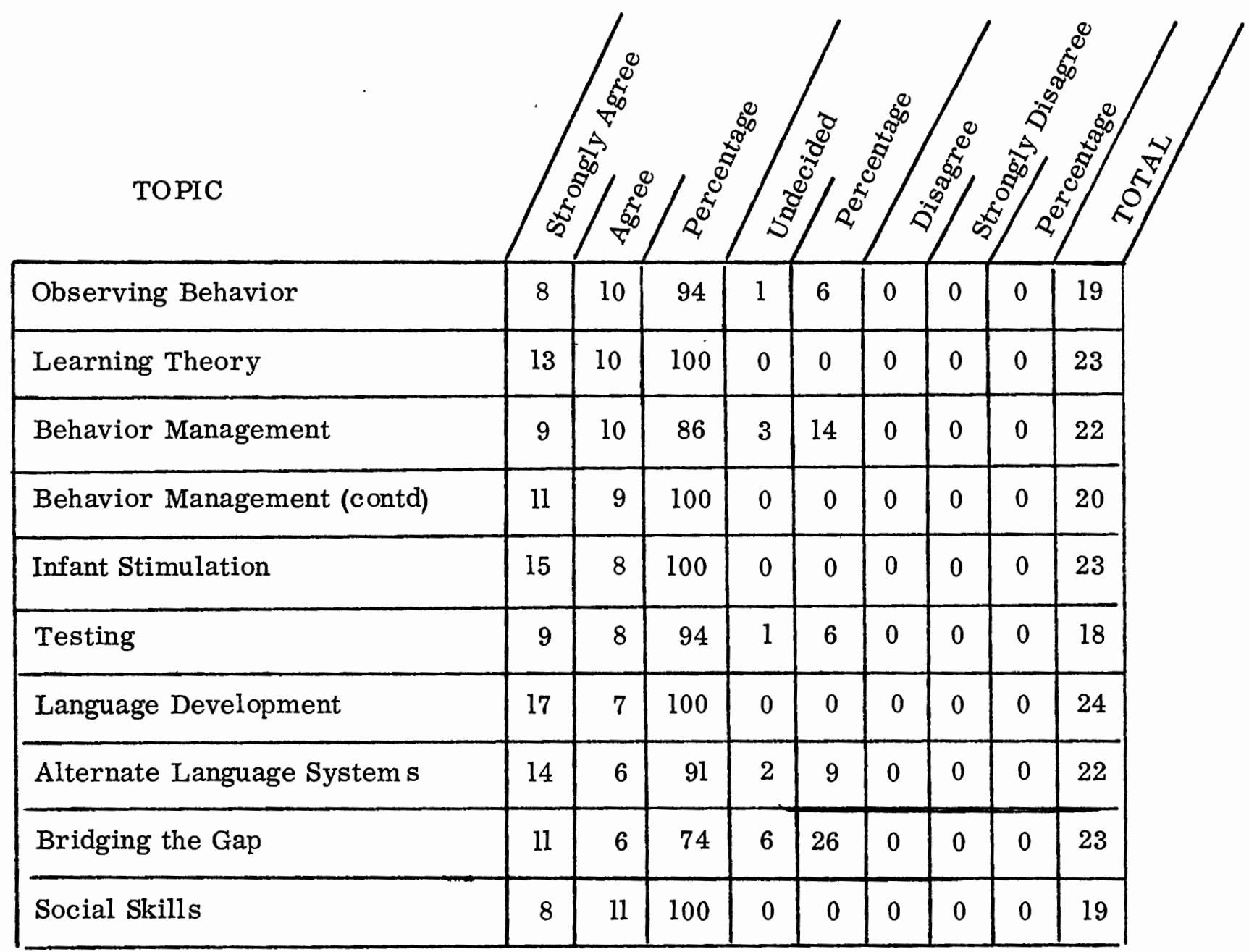


As noted in the preceding chapter, the "undecided" responses seem to indicate a reaction to whether the content was apropos to their foster children's age and disability as opposed to an indication that the content of the lecture was badly organized or lacking substance.

This assumption is reinforced by examining the pattern of response to question A, Part III: "Do you feel that the age group that your foster children are in was sufficiently covered in class?" ' Twenty-nine percent (seven) of the parents either replied "no" (four) to question A or were "undecided" (three). Seventy-one percent (17) replied affirmatively to the question. Judging from previous statements made by the parents, the twenty-nine percent were also the group who were undecided regarding the relevance of some class content to their own parent foster child situation.

The response to the statement regarding the instructor's accessibility was virtually unanimous. Ninety-six percent (23) of the parents "strongly agreed" that the instructor made herself available, four percent (1) "agreed" with the sta tement.

The response to question B "which topic was most helpful and/or informative. . " was much less variable than last term. In contrast to the dispersion of choices Fall term, three sessions all focusing on one topic "behavior management" got forty-eight percent of the responses. "Infant stimulation" was a distant second with a seventeen percent response. The lowest response was the session on "Testing" with only four percent of the total vote.

The concentration of interest on behavior management was also reflected in written comments made by the parents: 
"The (sessions on) behavior tactics have helped me to adjust to and better understand (my foster) child ...."

'I especially appreciated the (lecture on) special help for misbehaved (sic) insecure children."

"I found most helpful, positive guidance in the area of misbehavior ..."

"With acting-out teenagers in the home, the classes on behavior management were very helpful."

The desire for assistance with behavior management issues was also very evident in the responses to the final question in Part III "was there a topic you wish had been covered in class that was not?" One parent listed two specific situations in which he/she desired additional information:

"(1) How to deal with teenagers that have drug and/or related problems.

(2) A series on how to deal with the juvenile delinquent."

Additional comments included:

". . . wish more time had been spent on behavior modification . . . management of bizarre, if not psychotic behavior is a problem."

". . . motivation tactics and appropriate behavior away from home."

"More behavioral helps (sic) dealing with lying, stealing and misbehavior for added attention; how to change these."

"More defined (sic) guide on the behavior of theft and fibbing."

"I'd like to have more on behavior management."

Other topics listed by the parents were:

"I wish more time had been spent on information concerning Down's Syndrome infants or children."

"How do I as a foster parent dispel the fears of a youth that is being removed from my home?" 
"How do I allay the fears of a newly placed child in my home?"

It is evident then that the parents found the subject of behavior and its management as the most useful subject for their own utilization. Additionally, it appears that parents have a wide range of needs and concerns regarding this topic and to cover the material to the parents' satisfaction is indeed a challenge to the instructor.

\section{Part IV:}

The responses to the three statements in Part IV were overwhelmingly positive. Both Statement A ". . class positively helped my relationship with my foster children" and Statement C, ". . . information and training received in this class will assist me in my work with handicapped foster children, " received a positive endorsement of $100 \%$. Statement B regarding the student's "confidence as a foster parent after taking this class," received a $96 \%$ positive response as a result of one parent being "undecided." The parents' positive feelings regarding the winter sequence of classes was underscored by the tone of the comments made at the end of Part IV:

"This was an exceptionally good class. The instructor was good and a marvelous resource."

"The classes were all very good."

"Subject coverage (was) good for the varied background of the class members."

"Pam Berki is an excellent teacher in addition to being a knowledgeable clinician."

"The program was good; the instructor did a good job." 
"We had a super organized, well informed, instructor which kept great interest and worked hard. Thanks for a great opportunity."

"Pam was a very helpful teacher, the behavior tactics have helped me to adjust to and better understand, a child I was ready to give up on. After ten other foster homes this child did not need to be moved again, but I was just about to quit. The 'Task Analysis' was her salvation."

\section{RESULTS OF THE PRE AND POST "LEARNING TEST"}

The pre-test given to the parents on the first evening of class consisted of two parts. The first part contained a list of twelve terms associated with "skill development" and the management of behavior. Below this list were twelve definitions with which the parents were asked to pair up the term with the most appropriate definition. The latter part of the test presented the parents with five examples of negative behavior and four alternative modes for coping with each situation. The parents were instructed to "select the most appropriate thing to do if your child is doing one of the following . .."

The post-test, identical in content to the pre-test was administered to the parents the final session of class. All twenty-five of the parents present filled out the test ( $86 \%$ of the enrollment).

The results of the test tabulated by Ms. Berki were very positive. Nineteen of the twenty-five parents demonstrated positive improvement in terms of correct responses on the test. The mean improvement was just short of six $(5.8)$ correct answers. Thus a parent scoring nine on the pre-test could expect to score a 14.8 on the post-test. (For copy of the test see Appendix B) 
Of the remaining six tests, all six achieved perfect scores $(100 \%)$ on the pre-test and maintained that level on the post-test.

\section{TABLE ELEVEN}

PRE AND POST TEST RESULTS*

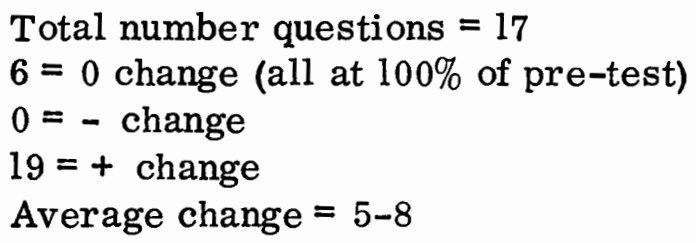

\begin{tabular}{rrrr} 
Students & Pre & Post & Point + Change \\
\cline { 2 - 3 } 1 & 12 & 17 & 5 \\
2 & 17 & 17 & 0 \\
3 & 17 & 17 & 0 \\
4 & 17 & 17 & 0 \\
5 & 17 & 17 & 0 \\
6 & 8 & 17 & 9 \\
7 & 13 & 17 & 4 \\
8 & 7 & 14 & 6 \\
9 & 9 & 17 & 8 \\
10 & 9 & 17 & 0 \\
11 & 17 & 17 & 4 \\
12 & 12 & 16 & 4 \\
13 & 11 & 15 & 3 \\
14 & 13 & 16 & 3 \\
15 & 12 & 15 & 10 \\
16 & 5 & 15 & 3 \\
17 & 9 & 12 & 2 \\
18 & 14 & 16 & 4 \\
19 & 13 & 17 & 4 \\
20 & 13 & 17 & 11 \\
21 & 6 & 17 & 0 \\
22 & 17 & 17 & 5 \\
23 & 7 & 12 & 6 \\
24 & 4 & 10 & 4 \\
25 & 12 & 16 & 102 \\
& & &
\end{tabular}

*Tabulated by Pam Berki (Winter Term Instructor) 


\section{ATTENDANCE}

Winter term attendance was excellent, with $21(73 \%)$ of the 29 parents attending at least eight of ten sessions. Ten of these 21 (35\% of the overall enrollment) attended all ten sessions. The remainder of the parents (27\%) attended over $50 \%$ of the classes with only one parent attending less than six classes (5).

The combination of positive attendance and the absence of any logistical problems in Part I or II suggests that the parents were not experiencing the logistical problems that some experienced last term. This suggests the possibility then that those parents who experienced complications with childcare and/or" transportation last term were unable to attend this term. To further verify this possibility a sample of parents who did not return from Fall term were contacted by phone with the results being reported in Chapter V.

\section{SUMMARY}

It is apparent again this term that the parents are generally quite satisfied with the structure and content of the class sessions. As was initially pointed out last term though, there are a number of parents who feel that their children's age group is not sufficiently covered in this class. This term it was reflected by the seven (29\%) parents who did not agree with the question pertaining to "sufficient coverage" of material in their child's age group. Few of the parents seem to overlap age group wise; the parents either care for infants and pre-adolescents or they concentrate exclusively on teenagers. This schism can produce potential problems for the instructor, particularly when planning course content. A possible 
means of dealing with this issue is for the instructor to poll the parents before the term begins as to the age group they work with and perhaps ask them to list what they as foster parents view as their most critical learning needs in working with their age group. Another option might be to offer two training tracks each track focusing on one age group of foster children.

The parents overwhelming selection of "behavior management" as the most helpful and informative subject covered, indicates a need for maintaining this subject as a focal point in future classes. A possible vehicle for assisting the parents in this crucial area could be the formation of an informal group of parents who might meet on a regular basis with an instructor, to discuss and share questions and concerns about the behavior management of their foster children.

Another potential use for groups would be providing an opportunity for parents to discuss informally the myriad of hand-outs and reading assignments given out over the term; several parents addressed this subject in the evaluation:

'We may be trying to cover too much material in this time period. Parents here are so busy they really don't have time to do home work . . ."

"There was a great deal of information covered - it was important to go into depth on any one topic - more topics would have spread time even thinner."

". . . felt like we had to rush which can't be helped in ten weeks."

Discussion groups could be organized after the end of the term by the parents themselves. These groups could meet perhaps on a monthly basis. This group format could serve as an excellent forum for the sharing of ideas and even more importantly as a source of mutual support and reassurance. 


\section{CHAPTER IV}

SPRING TERM

\section{DESCRI PTION OF CLASS}

Charlotte Duncan, Developmental Disabilities Service Coordinator for Multnomah County Mental Health, taught the Spring sequence, entitled "How to Get What You Need From the Community." Ms. Duncan described the class as having two main objectives:

"1) communications within the family unit and with agencies and professionals;

(2) learning about community resources available to foster parents and the handicapped children in their home . . emphasis will be on appropriate communication and use of resources."

In addition she described her expectations of the parents enrolled in the class as being:

"to complete reading assignments, make use of the annotated bibliography, participate in classroom activities, exercises and discussions and complete pre and post tests and evaluations."

Mrs. Duncan supplemented her own lectures with guest lecturers addressing a broad range of community social services and tactics useful in meeting the socio/medical needs of handicapped foster children.

\section{CLASS CONTENT}

The following is a brief description of class content:

March 28, 1978 "Introduction" 
April 3, 1978 Topic: "Communication"

Guest Lecturer: Kathy Hogan

The instructor discussed the basic elements of assertiveness training and how to enhance communication skills.

April 11, 1978 Topic: "More In Communication"

Guest Lecturer: Kathy Hogan

This session dealt with effective modes of communicating with professionals such as caseworkers, social workers, nurses and physicians. Included were both "face to face" and telephone communication.

April 18, 1978 Topic: "Advocacy and Legal Rights"

Charlotte Duncan and Guest Lecturers:

Sandy Kostrul - Foster Parent Association

Gerard Lobasco - Attorney, Developmental Disabilities Advocacy Center Advocacy rights for foster parents and handicapped children were explored. Included in the discussion was a description of "community advocacy programs" and national precedents regarding legal advocacy for right to treatment and equal access to education.

April 25, 1978 Topic: "Information and Referral and Training" Charlotte Duncan and Guest Lecturer:

Loren Hoffman, CSD Foster Parent Trainer

The instructors discussed the process by which parents can locate 
and enlist the assistance of those services most appropriate to their needs. In addition an exploration was made of the history of foster parent training, and possible models for next year's training sequence.

May 2, 1978 Topic: "Family Support and Counseling"

Charlotte Duncan and Guest Lecturers:

Stuart Brown, Multnomah County Mental Health

Ethlyn Pancratz, Multnomah Association for Retarded Citizens

Ms. Duncan began the class with a discussion of "twenty rules for

family communication." This was followed by a description of three mental health treatment modalities and how to secure competent mental health therapy. The session was concluded with a discussion of family support services.

May 9, 1978 Topic: "Education"

Guest Lecturers: Diana Devers, Portland Public Schools

Pat Sawyer, Multnomah Intermediate Education District

The instructors dealt with the implications of Law 94-142, equal education for handicapped children and how to communicate with educators your needs and concerns regarding your foster children.

May 16, 1978 Topic: "Recreation and Respite Care"/ "The Biological Parent"

Charlotte Duncan and Guest Lecturer:

Mary Douglas, Portland Bureau of Parks, Special Recreation

The first half of class covered the recreational opportunities for 
handicapped children, i.e., "Children Play to Grow Program," summer camps, "Special Olympics" and city parks programs. In addition the parents were apprised of the opportunities for "respite and relief care" for their handicapped children.

May 23, 1978 Topic: "Diagnosis and Evaluation and Medical Services"

Guest Lecturers: George Hall, Salem Evaluation Center

Carmen Carroll, Crippled Children's Division

The class session began with a lecture covering the process of a medical evaluation; diagnosis; psychological testing, and summary. The session concluded with a description of the medical services available to handicapped foster children and how to go about matching up the medical need with the best medical service.

May 30, 1978 Topic: "Wrap-up and Evaluation"

Guest Presentation: Ray Adams, Division of Continuing Education The parents were given a preview of the multi-media slide/tape produced by DCE, entitled: "How to Reach a Child." After the conclusion of the film the evaluation was administered.

\section{CLASS EVALUATION}

In order to maintain consistency, this evaluator retained the basic format of the two previous evaluations, with the focus once again on:

(1) the parents reaction to content and instruction;

(2) whether the class format promoted learning; and

(3) whether the content was apropos to the parents' own situation. 
The Spring term instructor was contacted for a description of class content and for her suggestions regarding the evaluation. Ms. Duncan expressed satisfaction with the present evaluation format so only minor modifications were made. These modifications consisted of discontinuing the questions pertaining to "logistical problems." This decision was a result of the lack of response to these questions Winter term.

The final evaluation was pared down to two parts. (Refer to Appendix A for a copy of the evaluation.) Part I consisted of a list of the topics presented by Ms. Duncan and the guest lecturers. The parents were again presented with the statement, used Fall and Winter terms: "The speaker's lecture was helpful and/or informative to me as a foster parent" and asked to respond to it by selecting one of five responses ranging from "strongly agree" to "strongly disagree." The final session was omitted from the topic list in the evaluation for there was no lecture that evening.

At the bottom of Part I were the three questions presented in the previous terms pertaining to class content: "was your children's age group sufficiently covered?" "which of the topics was most helpful and/or informative to your situation?" and "was there a topic you wish had been covered in class that was not?"

Part II was a repetition of the three statements presented in the Fall and Winter term evaluations. The first statement measured the influence of the class on the parents' relationship with their foster children; the second measured the effect of the class on the parents' self-confidence as a foster parent; the third was a measurement of whether the class enhanced the parent's skills as a foster parent. 
After the third statement the parents were encouraged to make "any additional comments" regarding the class.

Of the twenty-five parents enrolled in the class, twenty-one (84\%) were present at the final session and completed the evaluation. All twenty-one of the respondents had attended the previous term.

\section{EVALUATION RESULTS}

Part I:

The parents' responses to the nine sessions evaluated were very positive. Five (56\%) of the class sessions received a positive response (based on the combined totals of 'strongly agree' and 'agree') of greater than ninety percent with two receiving responses of $100 \%$. The lowest positive response was $81 \%$. Of 166 total responses to nine classes, there was only one "disagree" and twelve who were "undecided" about a specific class (see Table Twelve).

Two responses had to be discarded for they chose to respond twice to a class session by rating one speaker positively and the other negatively. It was in response to this same class session that one parent chose to "disagree" with the evaluation statement. In discussing the results with Ms. Duncan, she stated that the first speaker was warmly received as a result of her enthusiastic and informative presentation. Unfortunately, the second speaker chose to launch into a lengthy legal discussion, replete with esoteric terminology, a decision which alienated the speaker from his audience.

On an individual lecture basis the number of "Undecided" responses were 
slightly higher this term than Winter term. It is this evaluator's impression that this is a reflection of the parents' attempt to adjust to a number of speaking styles. This is in contrast to Winter term where the instructor taught all but one of the classes and received fewer undecided responses and a higher percentage of positive responses.

Another slight fluctuation in response trends this term occurred in question A of Part I: "Do you feel that the age group that your foster children are in was sufficiently covered in class?" Fewer parents this term indicated dissatisfaction with the degree of coverage of their child's age group. Nineteen percent (4) of the parents this term expressed dissatisfaction (3) or were undecided (1) regarding sufficient coverage. Twenty-nine percent (7) of the parents Winter term expressed dissatisfaction or were undecided. It is this evaluator's impression that the reduced percentage of dissatisfaction is a result of the content presented this term. The bulk of the lectures this term addressed issues of general concern to foster parents, eg., assertion skills and legal rights, as opposed to specific early developmental and behavioral information presented Fall and Winter term. This reduces then, the likelihood of neglecting the informational needs of those parents caring for older foster children.

Fifteen of the twenty-one respondents this term answered Question $B$ in Part I regarding: "which topic was most helpful and/or informative." Of the fifteen responses, $54 \%$ (8) chose the two sessions dealing with "Assertion Skills." The second most popular selection was "Education" with twenty-seven percent (4). of the responses. Three lecture topics each received seven percent (1): "Information 
and referral", "Respite Care" and "Mental Health." The concentration of interest again this term on one subject area seems indicative of a strong expression of need by the parents to focus on specific problem areas.

Written comments regarding this topic area included:

'T feel that I benefitted most from learning the methods of saying I disagree."

"The classes on assertive behavior were a big help to me . . I enjoyed the book also ..." (book on assertiveness, listed in the class bibliography)

A need for additional exploration of assertive communication skills were also expressed by parents in response to the final question in Part I: "Was there a topic you wish had been covered in class that was not?"

"I need to learn how to communicate more effectively with natural parents . . . and let them know what I feel their child needs . . ."

"How to talk to a natural parent without making them so angry they shut you out."

"I want to hear more about being an advocate for my foster child and talking more effectively with caseworkers . . ."

Other topics listed by the parents were:

"More information should be supplied on the process of permanent (sic) planning."

"T. E.D. procedures of enrollment for foster children."

". . more on psychology, more on educating (the) handicapped."

".. separation and grieving." 


\section{TABLE TWELVE}

Part I

"The Speaker's Lecture Was Helpful and/or Informative To Me As a Foster Parent."

\begin{tabular}{|c|c|c|c|c|c|c|c|c|c|}
\hline \multicolumn{10}{|l|}{ TOPIC } \\
\hline Introduction & 9 & 8 & 93 & 1 & 7 & 0 & 0 & 0 & 18 \\
\hline Communication (I) & 12 & 7 & 100 & 0 & 0 & 0 & 0 & 0 & 18 \\
\hline Communication (II) & 10 & 7 & 95 & 1 & 5 & 0 & 0 & 0 & 18 \\
\hline Advocacy and Legal Rights & 8 & 7 & 88 & 1 & 6 & 1 & 0 & 6 & 17 \\
\hline Information and Referral & 13 & 6 & 100 & 0 & 0 & 0 & 0 & 0 & 19 \\
\hline Family Support and Counseling & 5 & 8 & 81 & 3 & 19 & 0 & 0 & 0 & 16 \\
\hline Education & 9 & 6 & 88 & 2 & 12 & 0 & 0 & 0 & 17 \\
\hline $\begin{array}{l}\text { Recreation and Respite Care } \\
\text { The Biological Parent }\end{array}$ & 8 & 10 & 86 & 3 & 14 & 0 & 0 & 0 & 21 \\
\hline $\begin{array}{l}\text { Diagnosis, Evaluation and } \\
\text { Medical Services }\end{array}$ & 10 & 10 & 96 & 1 & 4 & 0 & 0 & 0 & 21 \\
\hline
\end{tabular}




\section{Part II:}

A strong positive tone was again evident this term in the parents' responses to the three statements in Part II. Both Statement B, regarding the students, ". . . confidence as a foster parent after taking this class," and Statement C, ". . . information and training received in this class will assist me in my work with handicapped foster children," received unanimous responses of $100 \%$. Statement A, ". . . class positively helped my relationship with my foster children," received a $90 \%$ positive endorsement. The remaining ten percent (2) were "undecided". It is this evaluator's opinion that the two undecided responses are a reflection of the scope of the sessions this term. The stress this term deviated further from an emphasis on the parent/child relationship than the two previous terms, thus potentially having less impact on the parents' relationship with their foster child.

A positive tone was also reflected in comments made by parents at the conclusion of Part II:

"The instructor did a marvelous job of finding helpful answers to foster parent problems."

"The teacher deserves an award for outstanding contributions to make (sic) our difficult tasks with raising handicapped children easier."

"The classes (were) quite beneficial to me. Hopefully there will be more like it."

"Very good class."

"Actually I found all of the classes most helpful." 


\section{ATTENDANCE}

Attendance Spring term, though not quite as strong as Winter term was still very good with sixty-eight percent (17) of the 25 parents enrolled, attending at least eight of ten sessions. Of the remaining thirty-two percent (8), twenty percent (5) attended at least five of the ten sessions. The final twelve percent (3) attended three classes each.

This evaluator was able to contact two of the three parents who attended only three classes. Apparently, they had attended classes together Fall term but because of concern regarding winter weather they decided not to attend Winter ter $\mathrm{m}$, to resume attendance in the spring. Unfortunately after the initial three sessions this term, they decided to drop the class as a result of "problems of distance and travel time." As noted in the preceding chapter this evaluator conducted phone interviews with a sample of parents who did not return after Fall term. The results will be discussed in the next chapter.

\section{SUMMAR Y}

In reviewing the parents' feedback this term, it seems quite evident that the parents are quite satisfied overall with the structure and content of the class sessions.

The most significant feedback this term was the parents' expression of interest in assertion and other communication skills. The application of which they view as critical in a broad range of situations. These situations would include: dealing with natural parents, advocating the needs of their foster children to the 
appropriate professionals in the community, and communicating effectively with their cas eworker.

One parent's wistful comment was very specific regarding assertion skills: "still wish I could rock the boat and not worry about losing my certification." This desire for additional work on communication skills could be very effectively addressed in a group format as described by this evaluator in the preceding chapter. It's introduction into a group format could serve as an effective vehicle for enhancing the parents' self-esteem and sense of professionalism. 


\section{CHAPTER V}

\section{SUMMAR Y AND RECOMMENDATIONS}

\section{SUMMARY}

In Chapter I, this evaluator listed five subject areas to be evaluated in the course of the three term training sequence. The following is a brief summary of the data collected in each subject area.

(1) Who is receiving the training?

The parents involved in the training program represented many years of experience in the field of foster parenting. Seventy-four percent of the 2I parents polled at the beginning of the year, had at least eight years of experience in foster care. The average age of the parents was fifty. Almost half of them (45\%) had five or more of their own children. Yet only four parents (19\%) had biologicial children who were handicapped.

(2) What are they learning?

The parents were exposed to a tremendous range of material in the 60 hours of training they received. The basic content of the class was designed to take the parents from neo-natal development with a comparison of normal and abnormal to the utilization of assessment tools, behavior management techniques, developmental skill acquisition and finally a review of community resources and the parents role as an advocate for their foster child's medical, emotional and educational needs. 
(3) What subject areas do the parents find most valuable?

During the fall term the parents chose a wide variety of areas as being of particular value to their own situation. These included: "three theories of child development," "motor development," "seizures and seizure control," "emotional problems of development, and "speech development."

In the Winter and Spring term sequences the parents overwhelmingly chose one specific area of interest and value. "Behavior management" was the subject deemed most important by the parents Winter term. In the Spring sequence, the parents selected "communication skills" as the subject they felt was of the most value to their respective situations.

(4) How effective is the training format in conveying information? And

(5) Is the training having any effect on the parents' relationship with their foster children?

It is this evaluator's impression that question four was most effectively answered by the pre and post test administered and authored by Pam Berki Winter term. The results of this test were very positive. Nineteen of the 25 parents demonstrated improvement in terms of correct responses on the test. The mean improvement was 5.8 correct answers. Of the remaining six parents all six had perfect scores $(100 \%)$ on both the pre and post tests.

Question number four also intended to include the degree of satisfaction the parents felt with the class location, meeting time, format and teaching aids. In addition, question four was intended as a means of determining whether transportation and/or childcare complications had affected the parents ' training experience. 
For the majority of parents $(70 \%$ attended twenty-four of thirty $(80 \%)$ class sessions) the class location and meeting time presented no major impediments to attendance. This assessment is reinforced by the lack of complaint by the parents Winter and Spring term regarding logistical problems. Unfortunately, this "lack of complaint" was a result of the fact that parents who were unable to solve childcare and/or transportation difficulties chose to drop out of the class. This evaluator contacted by phone a sample of the parents who dropped out of the training program prematurely to request feedback from them regarding the class and to discuss their decision to discontinue attendance. The following are some excerpts from those conversations:

" . . . I really enjoyed the classes but I had a lot of problems with childcare. I had to pay more than I was being reimbursed for a babysitter . . I I was reimbursed at a rate of two dollars an hour; when I had to pay at least three dollars an hour ... I also had trouble finding good competent care."

". . . I finally decided at the end of Fall term that I couldn't continue Winter term, it was just too far to travel. It took me two hours round trip to attend classes... I didn't get home from class sometimes till after ll:00 p.m."

". . . the type of foster children I care for made it difficult and expensive to find a good babysitter ... I always had to pay them extra . . . I also had trouble with transportation. I know most of the parents drive but I had to depend on the bus and if class ran late I missed my bus and got home awfully late . . ."

". . . I made it to most of the classes Fall term and thoroughly enjoyed them but I decided not to go Winter term because of the bad weather. We live on a farm and it takes an hour and a half to get to class in good weather . . . I decided to return Spring term but I missed all but one class because I couldn't afford to be away from the farm for so many hours ... If the class hadn't been so far away I could have made it to class a lot more often . . ." 
This evaluator also contacted a sample of parents who regularly attended class to get their impressions of the class format, teaching aids utilized in the training process, and whether the class had affected their relationship with their foster children.

". . many, many things were very helpful in the class ... We received an autistic child the same time as class started. We were able, because of what we learned in class, to apply behavior control techniques . . these techniques really helped our relationship with this young child."

". ... We had a seven year old girl who spoke very little because of an emotional disturbance. Because of the classes on communication and speech we were able to work with him very effectively."

"T liked the format of the class . . . It got my attention: It was very worthwhile."

"... the instructors got me doing more reading, thinking more about important issues with handicapped children."

'I liked the way the class was set up ... We had an opportunity to get to know the instructor and share our concerns and feelings with her about our foster children. . . but we also had a chance to benefit from many guest experts who shared their knowledge with us in a way that was down to earth yet very informative. .."

This sample of the feedback received is indicative of the positive feelings the parents had about the class and its format. It is unfortunate though that some parents were stymied in their attempt to attend class. For if future training sequences are to effectively serve all interested foster parents, barriers to attendance must be examined closely and realistically dealt with. 


\section{RECOMMENDATIONS}

In reviewing the areas of concern expressed by the parents the two major target areas that require attention are: logistical barriers which can impede attendance and how to most effectively reinforce and continue the growth and learning that the parents experienced in the training program.

As suggested in the summary to Chapter II, logistical barriers present a multi-faceted problem. One of the major problems is the amount of travel time parents must allot themselves, with the problem intensifying during the winter months. Travel distance becomes particularly critical when the training is available in only one location. A situation which necessitates the traveling of great distances. (eg., the mean travel distance Fall term was 52.7 miles) Unless this problem is addressed it will intensify as the program is expanded statewide.

This evaluator's recommendation would be to experiment with "satellite" classes within the four county area of Portland. These satellites could make use of already existing facilities such as churches, community colleges or high schools. With improved accessibility the parents would be able to cut down on travel time allotments and consequently the cost of childcare. In addition, car-pooling could be utilized as a means of assuring attendance by those who do not have a reliable mode of transportation. If this concept were successful it could be used as a model for application on a statewide basis.

Another significant barrier to attendance is the complications associated with childcare. A possible solution to this problem would be to develop a comprehensive list of competent sitters. This list would include those capable of dealing 
with handicaps which require specialized attention. In addition, with the introduction of satellite or community based classes, childcare at the class site might provide another possible alternative for parents.

As noted in previous chapters, the myriad of printed material and broad range of topics covered in the training sessions often frustrate the parent's attempts to expand his/her knowledge base and professional growth as a foster parent. Unless some vehicle is provided for discussion and assimilation of information beyond the conclusion of the training sequence, much of the material will be neglected. Many of the parents not only expressed concern about neglected material, but also dismay at not having enough time to adequately discuss those topics they felt were most crucial to their own situation.

It is this evaluator's opinion that the formation of an informal discussion group could serve as a useful forum for the parents to share questions and concerns, re: their own foster parent/child relationship. The group format could also be utlized as a means of pursuing subject areas deemed important during the training period. Assertion training and behavior management, two topics of particular interest to parents Winter and Spring term are examples of possible topic areas. The involvement of guest speakers and community professionals could lend a sense of professionalism to the group and contribute positively to the self-esteem of the participating parents. 


\section{FOOTNOTES}

1. President's Committee on Mental Retardation; MR '69: "Toward Progress, the story of a decade. Report of the PCMR." Washington, D.C. 1969.

2. Source: Thomas Orwick, CSD and Fairview State Hospital Laison.

3. Oregon Department of Human Resources. "An Overview of The Children Service's Division:" p. I, August, 1977.

4. Ibid, p. 13.

5. Ibid, p. 14.

6. Maluccio, A. N., "Foster Family Care Revisited; Problems and Prospects," Public Welfare 53(5), p. 17, 1974.

7. Ibid, p. 17.

8. Kline, Dazra and Overstreet, Mary F., "Foster Care of Children: Nurture and Treatment." (New York: Columbia University Press, 1972), p. 220.

9. Ibid, pp. 219-221.

10. A. N. Maluccio, Op. Cit., p. 16.

11. Ibid, p. 17.

12. Ibid, p. 17.

13. Leonard, Betty "HEW Grant 426; Foster Parent Training Proposal," p. 4. 14. Ibid, p. 4.

15. Advis ory Committee Meeting Notes: August 8, 1977, p. 1. 


\section{A SELECTED BIBLIOGRAPHY}

Close, K., "An Encounter With Foster Parents", Children Today, 18(4): pp. 138-42, 1971.

Galaway, B., "Clarifying the Role of Foster Parents", Children Today, 1(4): pp. 32-33, 1972 .

Garrett, Beatrice L., "Foster Family Services for Mentally Retarded Children", Children, 17(6): pp. 228-34, 1970.

Kline, Dazra, and Overstreet, Mary F., "Foster Care of Children: Nurture and Treatment", Columbia University Press, New York, 1972.

Levine, A. S., "Substitute Childcare: Recent Research and Its Implications", Welfare In Review, 10(1): pp. 1-7, 1972.

Maluccio, A. N., "Foster Family Care Revisited: Problems and Prospects", Public Welfare, 31(2): pp. 12-17, 1973.

Oregan, G. W., "Foster Family Care For Children with Mental Retardation", Children Today, 3(1): pp. 20-24 and 36-37, 1974.

Oregon Department of Human Resources, "An Overview of the Children's Services Department (pamphlet), August, 1977.

Petersen, J. C. and Pierce, A. D., "Socio-economic Characteristics of Foster Parents", Child Welfare, 53(5): pp. 295-304, 1974.

President's Committee on Mental Retardation: MR '69: Toward Progress: The Story of a Decade, Report of the PCMR, Washington, D. C., 1969.

Rice, D. L., "Foster Care for Emotionally Disturbed Children", American Journal of Orthopsychiatry, 38(3): pp. 539-42, 1968.

Taylor and Starr, "Foster Parenting; Integrative Review of the Literature", Child Welfare, XLVI pp. 371-85, 1967. 
APPENDIX A

\section{CLASS EVALUATIONS}


FOSTER PARENT TRAINING-PSU/DCE

Instructor: Diane Plumridge

Fall 1977

\section{CLASE EVALUATION AND SUKVEY}

\section{PAKT I}

1. What type of handicap or handicaps do your foster children
have?

2. Have any of them been diagnosed as being emotionally disturbed?

3. How many years have you been a foster parent?

4. Approximately how far do you have to travel round-trip
to attend this class?

3. Was transportation to class aproblem for you? describe the problems you experienced. .

If YES, please

6. Did you have any difficulty getting child care for your children? If so, could you describe these difficulties? 
PART II

The following is a list of the guest speakers who have lectured in your class this term. For each instructor listed, please answer the two statements below by circling $Q M E$ of five responses:

1. STRONGLY AGKEE - 2. AGREE 3. UNDECIDED 4. DISAGREE 5. STRONGLYDISAGREE

A. The speaker's lecture was helpful and or informative to me as a foster parent.

B. The speaker made her/himself available for questions and concerns during and after class.

$10 / 4 / 77$

TOPIC: "The Handicapped Child as a Person" A Group Discussion.

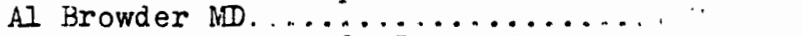

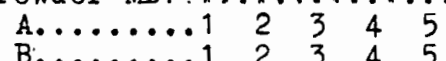

$10 / 11 / 77$

TOPIC:" Child Development \&s Viewed by Three Theories" and "Causes of Abnormal Behavior" Sue White Phd, and Honore Hughes PhD

$\begin{array}{lllll}\text { A.......... } & 2 & 3 & 4 & 5 \\ \text { B........ } & 2 & 3 & 4 & 5\end{array}$

$10 / 18 / 77$

IOPIC: "Speech Development- If only He Could Talk He"d be OK". Warren Fay PhD

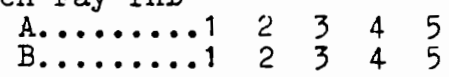

$10 / 25 / 77$

TOPIC: "Motor Development*How a Child Learns to Move His Body" Sue Giles RPT

$$
\begin{array}{lllll}
\text { A......... } 12 & 2 & 3 & 4 & 5 \\
\text { B........ } & 2 & 3 & 4 & 5
\end{array}
$$

$11 / 1 / 77$

TOPIE: "Seizures and Seizure Control" Mary Ellen StangerMD $\begin{array}{lllll}\text { A. ........ } & 2 & 3 & 4 & 5 \\ \text { B....... } & 2 & 3 & 4 & 5\end{array}$

$11 / 8 / 77$

TOFIC: "Feeding Clinic: the Mechanical and Nutritional Problems of a Hard to Feed Child." Elaine Lis Phd and Merry Meek iti; $\begin{array}{lllll}\text { A......... } & 2 & 3 & 4 & 5 \\ \text { B...... } & 2 & 3 & 4 & 5\end{array}$

$11 / 15 / 77$

TOPIC: "The Emotional Problems of Development as Viewed by Erickson," and "How to Deal with the Severely Deprived Child." Jack Hegrenes $\begin{array}{lllll}\text { A........... } & 2 & 3 & 4 & 5 \\ \text { B..... } & 2 & 3 & 4 & 5\end{array}$ 


\section{$-3-$}

PAK'L II (CONT)

$11 / 22 / 77$

TOPIC: "Sexual Development: The Normalization Process of Adolescence

and Emancipation" Jean Edwards Prescott PhD and Gerald Prescott DMD $\begin{array}{lllll}\text { A. } \ldots \ldots \ldots 1 & 2 & 3 & 4 & 5 \\ \text { B.........1 } & 2 & 3 & 4 & 5\end{array}$

Of the eight speakers who do you feel was the most helpful and/or

Who do you feel was the least helpful or informative?

Is there any one of these speakers that you would particulary like

to lecture again next term? If so, please place a large ' $X$ ' by
their name.

\section{PAite III}

To the following three statements please again respond by selecting

ONE Of ilve responses: 1. STRONGGIY AGREE 2. AGREE 3. UNDECIDED
4. DISAGREE 5. STRONGLY DISAGREE A. This class has positively helped my relationship with my foster
child/children. B. I feel more confident of myself as a foster parent, after
taking this class.

C. The information and training I have received in this class will assist me in my work with handicapped foster children.

Please describe a specific situation in which the training you have received in this class has helped you? (You may use the back of this sheet if you need more room) 
IF YOU HAVE MORE TO SAY ABOUT THE CLASS EITHER POSITIVE OR

NEGATIVE AND WOULD IIKE TO SHARE IT WITH THE EVALUATOR, PLEASE

PKINT THE FOLIOWING INFORMATION:

NANSE

ADDRESS

PHONE NUNBER

THANKYOU 
FOSTER PARENT TRAIHIHG* PSU-DCE .

IINSTRUCTOR: PAM BERKT

WINTER 1978

\section{CLASS EVAIUUAPION AND SURVEY}

PART I (PLEASE FILL OUT PART I, ONLY IF YOU DID IYOT ATTEND IAST TERM)

1. How many years have you been a foster parent?

2. Approximately how far do you have to travel round-trip to attend this class?

3. Was transportation to class a problem for you? If $\underline{Y E S}$, please describe the problems you experienced. .

4. Did you have any difficulty getting childcare for your. foster children? Children's Ages? If YES, could you describe these difficulties. . 
FOSTER PAREINT TRAINIHG* PSU/DCE

INSTRICTOR: PAU BERKI

WINTER 1978

CLASS RVLTULTION ADD STHTEI

PART II (PLEASE FILI OUT PART II ONLY IF YOU DID ATTEND LAST TERIA)

1. Was transportation to class last term a problem for you? If YES, have you found a. satisfactory solution this term? Please describe. .

2. Did you have any difficulty getting childcare for your foster children last term? Children's Ages? If YES, have you found a solution this term? Please describe. . 
FART III

The following is a list of topics covered by your instructor this term. For each topic listed, please respond to the statement below by selecting ONE of rive responses listed to the right of the topic:

IHE SPEAKER'S LECTURE WAS HELPFUL AMD/OR INFORIATIVE TO IIE AS A FOSTER PAREN

$$
\begin{aligned}
& \text { STIROIGLY AGREE -UNDECIDED . . DISLGREE STRON. } \\
& \text { IGKEE } \\
& \text { DISAG. }
\end{aligned}
$$

1/10 REGISTRATION

TOPIC: Observing Behavior

1

$2 \quad 3$

$4 \quad 5$

1/17 LEARIING THEORY

TOPIC: Pinpointing Behavior Setting Goals, Task inalysis, Reinforcement

2

4 5

$1 / 24$ BEHAVIOR TTHIMGEIEETT

TOFIC: Goals of Misbenavior, Classification of Eehavior

Problems, Rules of Thumb

$1 / 31$ EEHAVIOR MILNAGEMENT(CONT.)

TOIIC: Sinali. Group:

Behavior programs of young/ delayed chilaren

Eeravior programs for older cinildren

Fading Progaans, reinforcement

2.

3

4

5.

$2 / 7$ INFAITT STITULATION

TOPIC: DIST and what it tells

you

Portage Project and how to use it

Introduction to Down's Infant-

Parent Frogram

3

4

5

2/14 TESTING

i'OFIC: ihat to expect from test-

ing and how toget what you need.

Guest speaker: Dr. Y.A. IaClaire

2

3

4 
PART III (CONT.)

THE SPEAKER'S IECTURE WAS HELPPUL AND/OR INFORMGTIVE TO ME AS A FOS'IER PAREMV

$$
\begin{aligned}
& \text { STRONGIYY AGREE UNDECIDED DISAGREE } \\
& \text { AGREE }
\end{aligned}
$$

2/21 IANGUAGE DEVELOPIENT

TOPIC: How to facilitate lang-.

uage in the delayed child.

Alternative language systems

for the non-verbal child.

Small Group Fresentations

$\cdot 2$

3

4

5

2/28 ALTERTATE LAIGUAGE : SYSTGi:S(1st half)

Individual rork with students on request for speciric programe- Group Discussion

$3 / 7$ BRIDGIIG THE GAP

TOPIC: How tO WOrk with natural parerts, what to do to help your foster child's transition from one placement to another, how to deal with uncertaintities of place--.

4.

$3 / 14$ SOCIAI SKIIIS

TOPIC: Fow to help your child

develop appropriate public

beravior, make friends, avoid

"set ups".

12

3

4

5

* * The instructor made herself :available for question' and concerns auring and after class. $\quad \ldots \ldots \ldots \ldots \ldots \ldots$........

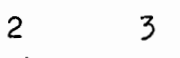

4

5 .

A. Do you feel that the age group that your foster children are in was suriciently covered in class?

B. Which of the for your situation?

C. Fas there a topic you wish had been covered in class that was not?

If so piease list the topic(s)... 
TO THE FOLLOWING THREE STATPEDNTS PLEASE RESPOND BY SEIECTIIG ONE OF THE FIVE RESPONSES LISTED TO THE RIGHT OF THE STATEVEITS:

A. This class has positively helped my relationship with my foster child/children........

B. I feel more confident of myself as a foster parent after

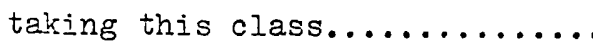

C. The information and training I have received in this class will assist me in my work with handicapped foster chilören ... 1

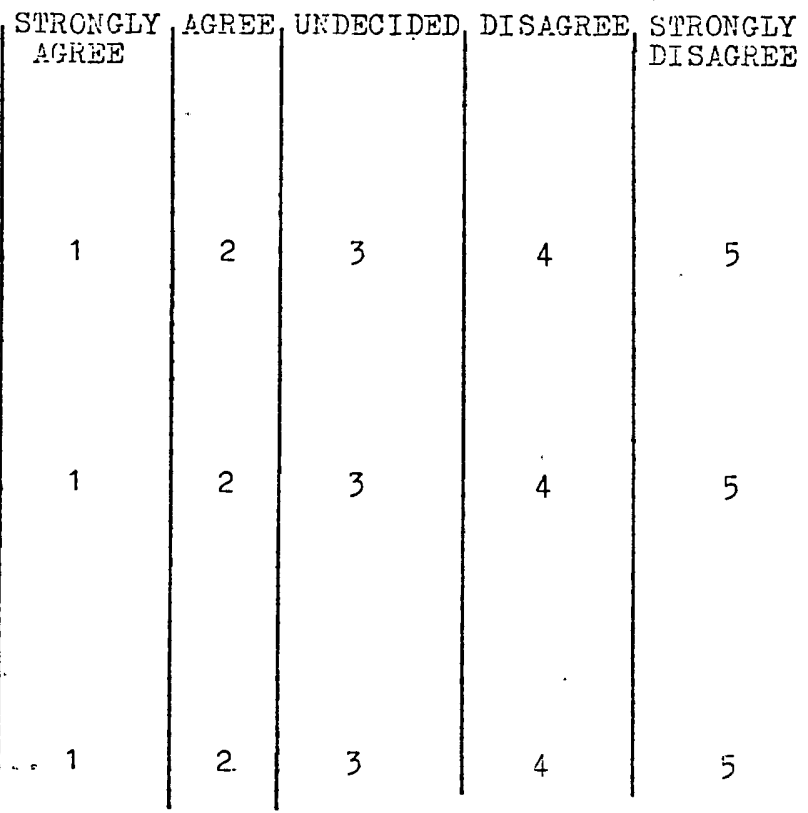

If you have any additional coments to make eitrer positive or negative, you are welccme to add them here... 
TO THE FOLLOWING THKEE STATENENTS PLEASE RESPOND BY SETECTING ONE OF THE FIVE RESPONSES IISTED TO THE RIGHT OF THE STATEMEITS:

A. This class has positively helped my relationship with my foster child/children.. ........

B. I feel more confiaent of myself as a foster parent after taking this class...............

C. The information and trainin $I$ have received in this class will assist me in my work with handicapped foster chiliren ... 1

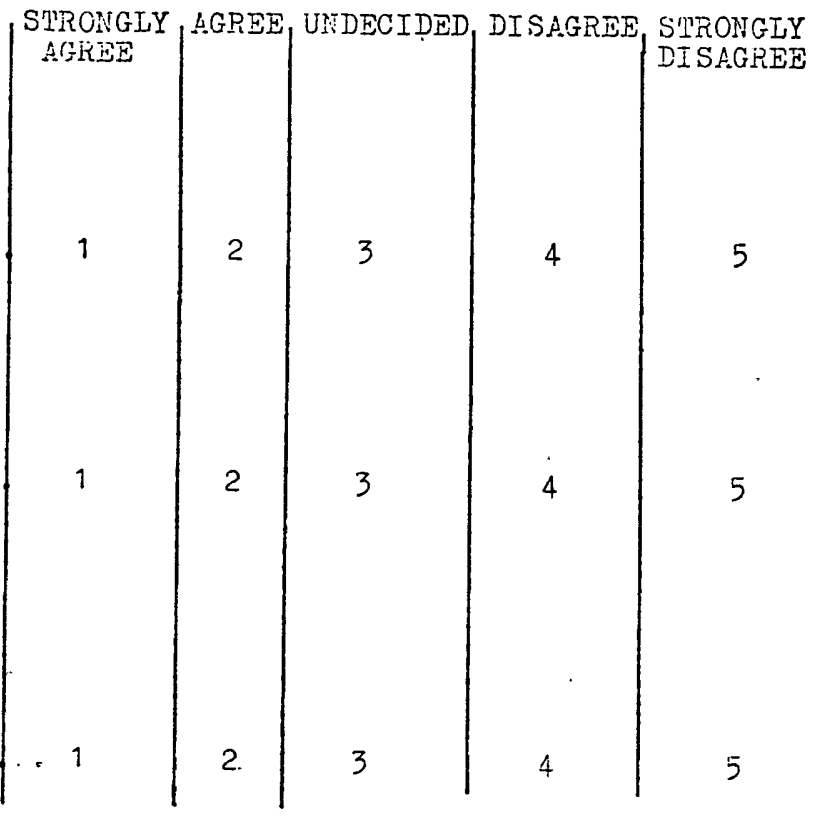

If you have any additional comments to make either positive or negative, you are welcome to add them here... 


\section{PART I}

SPRING TERM

The following is a list of topics covered by your instructor and guest lecturers this term. For each topic listed, please respond to the statement below by selecting ONE of five responses listed to the right of the
topic:

THE SPEAKER'S LECTURE TAS HELPFUI AND/OR INFORYATIVE TO ME AS FOSTEK PAREN'.

$\begin{array}{llll}\text { STRONGLY AGREE } & \text { UNDECIDED } & \text { DIS- } & \text { STRONGLY } \\ \text { AGREE } & & \text { AGREE } & \text { DISAGREE' }\end{array}$

3/28- INTRODUCTION

Discussion of class materials and topic areas.

$4 / 3$ TOPIC : COMMUNICATION

INSTRUCTOR : KATHY HOGAN

Assertiveness training.

4/11 TOPIC : COMMT'ICATION (CONT.)

How to communicate with caseworkers, medical professionals, and social workers. 4/18 TOPIC: ADVOCACY AND IESAI
SIGHTS

INSTRUCMORS: Charlotte Duncan

Sandy Kostrul, Foster Parent Assoc.

Gerard Lobasco, Attorney

Advocacy for foster parents and

handicapped children.

4/25 TOPIC: INFORMATION AND KE-
FEKRAL

INSTRUC'TORS: Charlotte Duncan

Loren Hoffman CSD Foster Parent

Trainer; How to get services.

who wili help, where are they?

Review of the history and future

of foster parent training 
PART I (CONT.)

THE SPEAKER'S LECTURE WAS HEIPFUI AND/OR INFORMA'TIVE TO ME AS A FOSTER PAHENT.

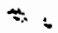

$\begin{array}{lll}\text { STRONGLY AGREE UNDECIDED " DIS- } & \text { STRONGL: } \\ \text { AGREE } & & \text { AGREE } \\ \text { DISAGRE }\end{array}$

$5 / 2$ TOPIC: FAMILY SUPPORT \&

COUNSELING

INSTRUCTORS: Charlotte Duncan

Stuart Brown, Mental Health

Ethelyn Pancretz, Multnomah Assn.

for Retarded Citizens

20 rules of family communication.

$A$ review of therapies. A dis-

cussion of family support services.

5/9 TOPIC: EDUCATION

Diana Devers, PortIand Pub. Schs.

Patricia Sawyer, Nult. Intermed.

Education District

New education for all handicapped

children. How to talk to educators. 1 . 2 . 3 . 4 . 4 . 5

5/16 TOPIC: RECREATION \& RESPITE

CARE THE BIOLOGICAL PARENT

INSTRUCTOKS: Chariotte Duncan

Mery Douglas, Portland Bureau of

Parks, Special Recreation.

Recreation for the handicapped

child. A discussion of relation-

ships with biological parents.

5/23. TOPIC: DIAGNOSIS AND EVAL-

UATION AND MEDICAL SERVICES

INSTRUCIORS: George Hall, Salem

Evaluation Center/ Carmen Car-

roll, CCD

what you can expect from an eval-

uation. How to pick the right

medical services.

+++ The instructors made themselves available for questions and concerns during and after class.

$\begin{array}{llll}2 & 3 & 4 & 5\end{array}$


PART I (CONT.)

A. Do you feel that the age group that your foster children are in was sufficiently covered in class?

B. Which of the topics do you feel was the most helpful and/or informative for your situation?

C. Was there a topic you wish had been covered in class that was not?

If so please list the topic(s)...

\section{PART II} TO THE FOLLOWING THREE STATEMENTS PLEASE RESPOND BY SELECTING ONE OF THE
FIVE RESPONSES IISTED TO THE RIGHT OF THE STATEMENTS:

$\begin{array}{llll}\text { STRONGLY AGREE } & \text { UNDECIDED } & \text { DIS- } & \text { STRONGIY } \\ \text { AGREE } & & \text { AGREE } & \text { DISAGREE }\end{array}$

A. This class has positively

helped my relationship with my

foster child/children.

.

B. I feel more confident of

myself as a foster parent after

this class. . . .

1

23

$4 \quad .5$

C. The information and train-

ing I have received in this class

will assist me in my work with

handicapped foster children. .

2

+++ If you have any additional comments to make either positive or negative, you are welcome to add them here... (if additional space is needed, you may use the back of this sheet) 


\section{APPENDIX B}

PRE AND POST TEST

WINTER TERM 


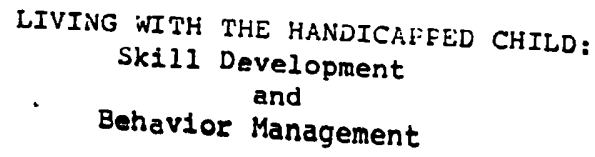

NAME:

DATE:

1. Please write the following terms in the blanks in front of the
best definition:

non-compliant behavior positive reinforcement task analysis

behavior

total communication

DDST

rue

token economy

conseçuence

aggressive behavior

time-out

self indulgent behavior

Any observable and measurable actior.

Skill or behavior broken Into small sequenced steps for successful teaching.

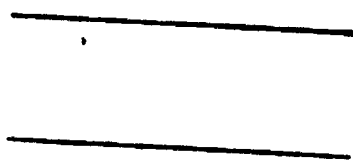

Peedback immediately following a behavior that
Increases or decreases a behavior's occurence

Hitting, kicking, spitting, biting....inappropriate
behavior that directly affects

behavior that directly affects another individual.

Developmantal screening test for children birth
to six years. Use of verbal language, pictures, sign language,
written language in combination

Consequence that increases or strengthens a
behavior. 
1. (cont.)

"I don't want to", "I don't have to", "I won't".

Signal or request that influences the occurence of a behavior

Withholding reinforcers, 1gnoring inapproprlate behaviors, removal from a reinforcing setting.

A reinforcement system set up in which tangible objects are used asrewards to be later exchanged for desired objects or activities.

Tantruming, : pouting, sulking, whining.

2. Select the most appropriate thing to do if your child is doing one of the following:

A. Michael frequently hits other children $1 f$ they are playing with toys he wants. Which consequence should you use when Michael does this?

Ignore Michael

Spank Michael so that he will learn not to hit

Give him the toy he wanted

Remove Milchael and make him sit in the corner

B. Jimmy has frequent tantrums. The most effective thing to do to decrease the number of tantrums is:

Fick Jimmy up. and hold him on your lap.

Ignore him.

Spank him.

Try to talk with Jimmy and explain why he shouldn't. behave that way 
2. (cont.)

E. Four year old Sarah refuses to pick up her toys. To teach Sarah to do as she 1s asked, you should:

Physically assist Sarah in picking up the toys and praise her when she completes the job.

Spank her and take the toys away from her for a week.

Talk with Sarah and explain the importance of learning to be responsible

Do it yourself and decide against trying to teach Sarah to do it. After all, four years old ismuch too to do something like picking up her toys.

D. Linda is just beginning to Jearn to dress herself but st121 has trouble getting her shirt on by herself. You should:

___ Do it for her so she won't get discouraged

Leave her alone and let her figure out how to get her shirt on one way or another

Find out how much she car do alone and praise her for doing that much. Assist her with the rest.

Tell Linda she can not have breakfast until she completely dresses herself. of course you would let her have breakfast anyway, even if she doesn't manage to get dressed.

E. You received a new six year old foster child about two months. ago. This child doesn't have any clear words but does make a lot of individual sounds. What should you do to encourage language development in your child?

Talk with the child, using long sentences and as many different words as possible so that he will get used to the way language should sound.

Talk baby talk with the child because this is closer to his developmental level and should be easier for him to understand.

Don't do anything. The child will ta:k when he is ready and axything you could do would probably just confuse him anyway.

Select several common objects which the child likes and rocuire that he attempt an approximate label before he can have the object. 
3. This section is for you to fill out so that I can direct this course toward the areas which you feel would be most useful to you.

A. The most difficult problem I have had with foster children 1s: (i.e. behavior problems, feeding problems, working with the parent, etc.)

B. The area I am most interested in learning more about this term is: (i.e. infant stimulation, how to understand the kinds of tests my child has been given, how to help my child communicate,
etc.)
C. Elease write any additional comments and idess you have that would be helpful in planning this course so that it will cover topics you are most interested in knowing more about. 
APPENDIX C

PARENT PROFILE

WINTER TERM 
(DO NOT PUT YOUR NAME ON THIS SHEET!!)

SPECIAL FOSTER PARENT TRAINING PROGRAM QUESTIONAIRE

PLEASE ANSWER THE FOLLOWING INFORMATION:

$\therefore:$

$\mathrm{AGE}$

HIGHEST GRADE COMPLETED IN SCHOOL

DO YOU CONSIDER YOURSELF A MEMBER OF A MINORITY GROUP? $\because \ldots \ldots$

- WAS YOUR FAMILY'S NET INCOME IAST YEAR, IESS THAN $\$ 5,000$

MORE THAN\$5,000 BUT LESS THAN $\$ 10,000$

MORE THAN $\$ 10 ; 000$ BUT LESS THAN $\$ 15,000$

MORE THAN $\$ 15,000$ BUT' LESS THAN $\$ 20 ; 000$

$\times$ MORE THAN $\$ 20,000$

DO YOU HAVE ANY CHILDREN OF YOUR OWN? HOW MANY? ARE AIY OF YOUR OWN CHIIDREN HANDICAPPED?

DID YOU ATTEND THIS CLASS IAST TERM?

THANKYOU FOR YOUR ASSISTANCE!! 